\title{
INDICADORES DE QUALIDADE DE SOLOS EM ÁREA DE MINERAÇÃO E METALURGIA DE CHUMBO. I - MICRORGANISMOS ${ }^{(1)}$
}

\author{
Yara Jurema Barros ${ }^{(2)}$, Vander de Freitas Melo ${ }^{(3)}$, Jair Alves \\ Dionísio $^{(3)}$, Edilson Batista de Oliveira ${ }^{(4)}$, Leandro Caron ${ }^{(5)}$, Larissa \\ Kummer $^{(6)}$, Júlio César Rodrigues de Azevedo ${ }^{(5)} \&$ Luiz Cláudio de \\ Paula Souza ${ }^{(3)}$
}

RESUMO

Os microrganismos são os mais numerosos da fração biológica do solo e estão sujeitos a alterações em sua abundância e nas relações metabólicas em função de mudanças ambientais, como o aporte de poluentes ao solo. O objetivo deste trabalho foi avaliar a atividade microbiana de solos da área de mineração e metalurgia de chumbo (Pb), no município de Adrianópolis (PR), a fim de gerar indicadores biológicos da qualidade desses solos. Os solos foram amostrados (0 a 5 e 5 a $10 \mathrm{~cm}$ ) em cinco locais e em quatro épocas do ano (maio, setembro, novembro e janeiro). Os teores totais de $\mathrm{Pb}$ e $\mathrm{Zn}$ do solo foram determinados por espectroscopia de emissão atômica com plasma acoplado indutivamente, após digestão das amostras com $\mathrm{HF}$ e $\mathrm{HNO}_{3}$ concentrados e $\mathrm{H}_{2} \mathrm{O}_{2} 30 \%(\mathrm{v} / \mathrm{v})$ em forno de micro-ondas. Para extração de formas mais disponíveis de $\mathrm{Pb}$ e $\mathrm{Zn}$ foi empregada a solução de $\mathrm{HNO}_{3}$ 0,5 mol $\mathrm{L}^{-1}$ fervente. Foram estimados os seguintes atributos microbiológicos dos solos: contagem de bactérias totais (BT); contagem de bactérias esporuláveis (BESP); percentagem de bactérias esporuláveis em relação à $\mathrm{BT}$; contagem de fungos; relação entre fungos e bactérias totais; respiração microbiana; biomassa microbiana; percentagem do carbono microbiano em relação ao C orgânico total do solo; e quociente metabólico. Utilizaram-se três métodos para o tratamento estatístico dos dados: diferenciação dos solos por meio da análise de componentes principais (ACP); obtenção de índice de qualidade ambiental relativo aos atributos microbiológicos (IQAMi); e análise de correlação simples. A elevada fertilidade dos solos tornou menos expressivo o efeito prejudicial dos metais pesados sobre os

(1) Parte do trabalho de mestrado do primeiro autor apresentado ao Programa de Pós-Graduação em Ciência do Solo, Universidade Federal do Paraná. Recebido para publicação em julho de 2009 e aprovado em maio de 2010.

(2) Mestre em Ciência do Solo, Universidade Federal do Paraná - UFPR. Rua dos Funcionários 1540, Juvevê, CEP 80035-050 Curitiba (PR). E-mail: yarajuba@gmail.com

(3) Departamento de Química e Biologia, Universidade Tecnológica Federal do Paraná - UTFPR. Av. Sete de Setembro 3165, CEP 80203-901 Curitiba (PR).E-mails: leandrocaron@hotmail.com; jcrazevedo@utfpr.edu.br

(4) Departamento de Solos e Engenharia Agrícola, UFPR. Bolsista CNPq. E-mail: vanderfm@ufpr.br; jair@ufpr.br; lcsouza@ufpr.br

(5) Embrapa Florestas, Estrada da Ribeira, km 111, Caixa Postal 319, CEP 83411-000 Colombo (PR). E-mail: edilson@cnpf.embrapa.br

(6) Departamento de Engenharia Ambiental, UTFPR. E-mail: lkummer@utfpr.edu.br 
microrganismos. Contudo, no mês de maior estresse climático para os organismos (maio - menor temperatura), solos com maiores teores de $\mathrm{Pb}$ apresentaram menor população e atividade microbiana, ou seja, nessas condições as bactérias e fungos foram bons indicadores de qualidade do solo. A maior proporção de BESP nos solos mais contaminados por $\mathrm{Pb}$ no mês mais frio (correlação de $0,95^{*}$ para maio) pode ser interpretada como mecanismo de resistência desses organismos. O IQAMi na camada de 0 a $5 \mathrm{~cm}$ foi mais eficiente que a ACP na separação dos solos contaminados com metais pesados: os valores decresceram em sentido oposto ao aumento nos teores de $\mathrm{Pb}$ dos solos. Já na profundidade de 5 a $10 \mathrm{~cm}$ a ACP foi mais eficiente para esse propósito.

Termos de indexação: bioindicadores, contaminação ambiental, metais pesados.

\title{
SUMMARY: SOIL QUALITY INDICATORS IN LEAD MINING AND METALURGY AREA. I - MICRORGANISMS
}

\begin{abstract}
Microorganisms are the most numerous organisms in the soil biological fraction. Their population and metabolic relations are affected by environmental changes, such as pollutant deposition on and movement into the soil. The aim of this work was to assess the soil microbial activity in a Pb mining and metallurgy plant, in Adrianópolis (PR), to determine soil biological quality indicators. The soil (layers 0 to 5 and 5 to $10 \mathrm{~cm}$ ) was sampled once at five locations four times (May, September, November and January), approximately, 62 years after mining activity and 12 after the activity was stopped. The total $\mathrm{Pb}$ and $\mathrm{Zn}$ content in the soil was determined through inductively coupled plasma - atomic emission Spectrometry (ICP-AES), after microwave digestion of the soil samples with concentrated $\mathrm{HF}, \mathrm{HNO}_{3}$ and $30 \%(\mathrm{v} / \mathrm{v})$ $\mathrm{H}_{2} \mathrm{O}_{2}$. To extract the heavy metals in bioavailable form, a boiling $\mathrm{HNO}_{3} 0.5 \mathrm{~mol} \mathrm{~L}^{-1}$ solution was used. The following soil microbial parameters were estimated: Total Bacteria (TB); Sporulating Bacteria (SB); percentage of Sporulating Bacteria comparing to TB; Fungi; correlation between fungi and TB; Microbial respiration; Microbial Biomass; Microbial Carbon percentage compared to the soil total organic C; Metabolic quotient. Three methods were used to the statistical data analysis: (a) differentiation of the sites trough Principal Component Analysis (PCA); (b) establishment of an Environmental Quality Index (EQMI) based on microbiological parameters; and (c) simple correlation analysis. The the heavy metal effect microorganisms was minimized by the high soil fertility. However, in the month with the most unfavorable climatic conditions for the microorganisms (May-lowest temperatures), soils with the highest $\mathrm{Pb}$ showed reduced microorganism population and microbial activity, which means that under these conditions bacteria and fungi were good soil quality indicators. The highest $S B$ proportion in the most Pb contaminated soils in the coldest month (0.95* correlation to May) can be interpreted as a resistance mechanism of these organisms. The environment microbial quality index (EMQI) in the 0 to $5 \mathrm{~cm}$ layer was more efficient than PCA in distinguishing locations with heavy metal contamination: the values decreased in the opposite sense to the increase in the soil Pb. However, in the 5 to $10 \mathrm{~cm}$ layer PCA was more efficient to this purpose.
\end{abstract}

Index terms: biological indicators, environmental contamination, heavy metals.

\section{INTRODUÇÃO}

O solo é um corpo vivo e todos os seus processos e componentes estão funcionalmente integrados. Os processos vitais são expressos e regulados pela biota do solo. Essa regulação da biota dá-se sobre a decomposição de resíduos orgânicos, ciclagem de nutrientes, degradação de poluentes, além de sua forte influência na agregação do solo. Isso faz com que esses organismos e os processos relacionados sejam naturalmente escolhidos como indicadores da qualidade do solo (Papendick \& Parr, 1992).
Os metais pesados acumulam-se no ambiente, principalmente em solos e sedimentos de áreas contaminadas, e podem causar toxidez aos microrganismos (Obbard \& Jones, 1993) e demais organismos da cadeia trófica (Accioly \& Siqueira, 2000).

Os microrganismos são os componentes mais numerosos da fração biológica do solo. Nos ecossistemas naturais a diversidade e o número de microrganismos apresentam pequenas oscilações, resultantes das alterações ambientais (Cardoso, 1992). Dick et al. (1996) propuseram o monitoramento da população e atividade microbiana do solo como 
indicador da qualidade do solo, pois são muito sensíveis a interferências do ambiente, como incrementos na concentração de metais pesados. Outros autores destacaram a importância da diversidade da comunidade microbiana nos ecossistemas terrestres como um indicador do estresse advindo da contaminação por metais pesados (Doelman et al., 1994; Liao et al., 2005).

Alguns metais-traço, como Zn, $\mathrm{Cu}$, Ni e Co, são essenciais para as plantas, animais e microrganismos, mas requeridos em pequenas quantidades (Chaudri et al., 1992). Entretanto, deve-se considerar que todos são potencialmente tóxicos em concentrações elevadas, provocando desnaturação de proteínas e bloqueios de sítios de ligação de enzimas (Siqueira et al., 1994). Cd, $\mathrm{Pb}$ e $\mathrm{Sn}$ são tóxicos na forma de cátions e tendem a ser ainda mais tóxicos quando estão ligados às substâncias orgânicas (Summers \& Silver, 1978).

De modo geral, os metais pesados possuem influência negativa sobre os processos mediados biologicamente do solo (Lee et al., 2002), como as transformações de compostos nitrogenados, principalmente reduzindo a taxa de nitrificação (Munn et al., 2000), a decomposição microbiana da celulose (Chew et al., 2001) e a mineralização da matéria orgânica do solo (Reber, 1992).

Papendick \& Parr (1992) relataram que índices microbiológicos baseados em mais de um atributo são capazes de discriminar o efeito de diferentes tipos de manejo sobre a qualidade do solo, e, nesse caso, os quocientes microbiano e metabólico são ótimos indicadores. $\mathrm{O}$ quociente metabólico $\left(\mathrm{qCO}_{2}\right)$ é a taxa de respiração basal por unidade de biomassa microbiana $\left(\mathrm{CO}_{2}\right.$ liberado/C biomassa), que é calculada pela relação entre a quantidade de $\mathrm{CO}_{2}$ desprendido da amostra de solo incubada e a quantidade de $\mathrm{C}$ da biomassa microbiana (Walker \& Reuter, 1996).

Altas concentrações de metais pesados promovem inibição da atividade das populações de diversas bactérias e fungos, alterando de imediato o equilíbrio microbiológico do ecossistema (Reber, 1992 ; Landmeyer et al., 1993). Observa-se tendência à diminuição da diversidade genética das populações bacterianas (Hirsch et al., 1993), já que o acúmulo de metais pesados reduz a relação bactéria/fungo, pois os fungos costumam ser mais resistentes a esses elementos (Mergeay, 1995). Ocorre concentração de número de bactérias gram-negativas e esporuláveis (Duxbury \& Bicknell, 1983) e também decréscimo da relação C microbiano/C orgânico total do solo (Valsecchi et al., 1995).

O objetivo deste trabalho foi avaliar a atividade microbiana de solos de área de mineração e metalurgia de $\mathrm{Pb}$, no município de Adrianópolis (PR), a fim de gerar indicadores microbiológicos da qualidade destes solos.

\section{MATERIAL E MÉTODOS}

\section{Área de estudo, amostragem dos solos e preparo das amostras}

A área de mineração e metalurgia de $\mathrm{Pb}$ situa-se no município de Adrianópolis (PR), na localidade de Panelas de Brejaúvas, distante $12 \mathrm{~km}$ da sede do município e próxima às margens do rio Ribeira, na divisa com o Estado de São Paulo. Em 1995, após 50 anos de atividade, uma empresa mineradora encerrou suas atividades, deixando a céu aberto, sem nenhuma proteção, aproximadamente $177 \mathrm{Gg}$ de resíduos de beneficiamento de $\mathrm{Pb}$ (Eysink, 1988). Na área era evidente a grande degradação do meio ambiente, com ocorrência de intenso processo erosivo, facilitado pelo relevo acidentado (Figura 1), grande número de bocas de túneis de mineração, estradas degradadas, extensas áreas com escórias do beneficiamento de $\mathrm{Pb}$ espalhadas sobre o solo e abandono da fábrica.

A compartimentalização da paisagem em unidades mais homogêneas, com menor variabilidade das classes de solos, usando o geoprocessamento, e a identificação de diferentes ambientes em função da forma de contaminação possibilitaram uma

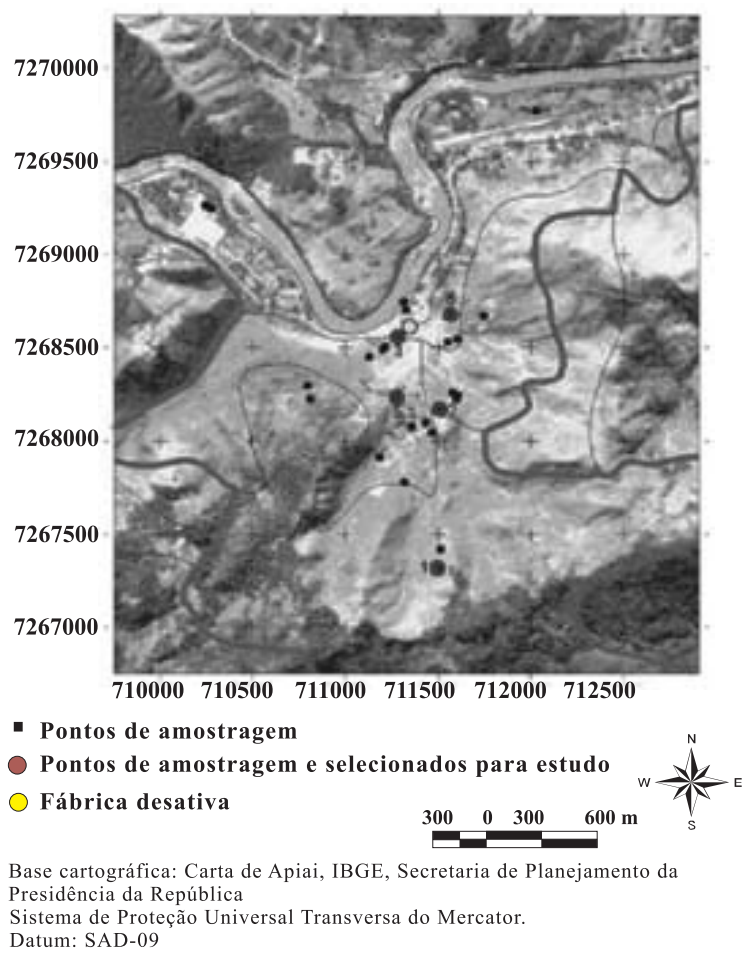

Figura 1. Foto aérea georreferenciada com os compartimentos geomorfológicos (linhas mais finas), localização da fábrica abandonada e locais de coleta $(1,2,3,5$ e 6$)$ dentro da área selecionada para o estudo (linha mais espessa). Os pontos menores representam a coleta prévia de solos para reconhecimento da área e definição dos ambientes em função das diferentes formas de contaminação, conforme detalhes apresentados por Andrade et al. (2009a). 
amostragem mais representativa da área sob influência direta das atividades de mineração e metalurgia de $\mathrm{Pb}$ (linha mais espessa na Figura 1). Os critérios para seleção dos locais de amostragem dos solos foram apresentados por Andrade et al. (2009a) e suas características encontram-se no quadro 1.

O mineral de interesse econômico na área foi a galena $(\mathrm{PbS})$, com ocorrência de veios do mineral nas rochas da região. A quadrícula de Adrianópolis apresenta geologia complexa, com as seguintes formações e litologias, em ordem decrescente de ocorrência (Oliveira et al., 2002): (1) complexos granitoides (Três Córregos e Cunhaporanga); (2) dolomitos e carbonatos com baixo grau metamórfico; (3) rochas vulcano-sedimentares, com domínio de rochas psamopelíticas; (4) carbonatos e rochas psamopelíticas; (5) gnaisses variados, xistos e quartzitos de baixo a médio grau metamórfico; e (6) metabrechas, metaconglomerados e metapelitos.

Foram realizadas quatro coletas ( 22 de maio, 3 de setembro e 26 de novembro de 2007 e 28 de janeiro de 2008) em quadrantes no entorno dos pontos selecionados (Figura 1 e Quadro 1). A área estabelecida para a retirada da amostra composta de solo em cada época foi de 1,5 x 1,5 m. O objetivo das quatro coletas ao longo do tempo foi avaliar a flutuação

Quadro 1. Localização, classificação dos solos e características dos locais de amostragem identificadas em campo

\begin{tabular}{|c|c|c|c|c|c|}
\hline \multirow[b]{2}{*}{ Solo } & \multicolumn{2}{|c|}{ UTM (22J) } & \multirow[b]{2}{*}{ Altitude } & \multirow[b]{2}{*}{ Classe de solo } & \multirow[b]{2}{*}{ Observações } \\
\hline & $\begin{array}{l}\text { N-S (m) } \\
\text { Latitude }\end{array}$ & $\begin{array}{l}\text { E-W (m) } \\
\text { Longitude }\end{array}$ & & & \\
\hline 1 & $7267313 \mathrm{~S}$ & $711502 \mathrm{~W}$ & $546 \mathrm{~m}$ & $\begin{array}{l}\text { Neossolo } \\
\text { Litólico }\end{array}$ & $\begin{array}{l}\text { Solo de referência sob mata nativa. Graças à } \\
\text { grande altitude do local em relação à fábrica } \\
\text { (diferença de cota de } 380 \text { m), não havia } \\
\text { evidências da influência direta das atividades } \\
\text { de mineração no solo. }\end{array}$ \\
\hline 2 & 7268164 & 711513 & $326 \mathrm{~m}$ & $\begin{array}{l}\text { Cambissolo } \\
\text { Háplico }\end{array}$ & $\begin{array}{l}\text { Localizado em posição intermediária da } \\
\text { encosta, representando condição onde ocorreu } \\
\text { incorporação de rejeito grosseiro e de coloração } \\
\text { escura no perfil de solo, devido à deposição de } \\
\text { colúvio das áreas mais altas. Cobertura } \\
\text { vegetal composta por grama-batatais } \\
\text { (Paspalum notatum) na maior parte de sua } \\
\text { extensão. }\end{array}$ \\
\hline 3 & 7268555 & 711287 & $165 \mathrm{~m}$ & $\begin{array}{l}\text { Neossolo } \\
\text { Litólico }\end{array}$ & $\begin{array}{l}\text { Localizado próximo à fábrica, com grande } \\
\text { volume de serapilheira, com os horizontes do } \\
\text { solo preservados e sem incorporação de } \\
\text { rejeitos sólidos. Esse local representou os solos } \\
\text { que potencialmente receberam deposição de } \\
\text { material particulado oriundo do processo de } \\
\text { fusão do Pb, por meio da emissão de fumaça } \\
\text { pelas chaminés. Cobertura vegetal composta } \\
\text { por árvores da família das leguminosas } \\
\text { (Leucaena sp.) e capim-colonião (Panicum } \\
\text { maximum) no sub-bosque. }\end{array}$ \\
\hline 5 & 7268070 & 711360 & $316 \mathrm{~m}$ & $\begin{array}{l}\text { Mistura de solo } \\
\text { mais rejeito } \\
\text { grosseiro }\end{array}$ & $\begin{array}{l}\text { Pilhas de rejeitos na superfície do solo e } \\
\text { resíduos ainda frescos visivelmente } \\
\text { incorporados ao perfil. A cobertura vegetal, } \\
\text { assim como do local } 2 \text {, era constituída de } \\
\text { grama-batatais (Paspalum notatum), em sua } \\
\text { maior parte, entretanto menos viçosa que no } \\
\text { local } 2 \text {. }\end{array}$ \\
\hline 6 & 7268671 & 711572 & $202 \mathrm{~m}$ & $\begin{array}{l}\text { Neossolo } \\
\text { Quartzarênico }\end{array}$ & $\begin{array}{l}\text { Encontrava-se sob condições similares às do local } \\
3 \text {, próximo à fábrica e sujeito à contaminação } \\
\text { com Pb particulado pela deposição } \\
\text { atmosférica. A cobertura vegetal do local } 6 \text { é } \\
\text { de mata secundária, e as espécies } \\
\text { preponderantes são diferentes do local 1, } \\
\text { destacando-se samambaias (Pteridium } \\
\text { aquilinum) e capim-elefante (Pennisetum } \\
\text { purpureum) no sub-bosque. }\end{array}$ \\
\hline
\end{tabular}


biológica dos solos devido, principalmente, às alterações nas condições climáticas (Figura 2). Para obtenção da amostra composta (aproximadamente $3 \mathrm{~kg}$ de solo para cada profundidade) foram homogeneizadas cerca de 10 amostras simples, retiradas de 0 a 5 e de 5 a $10 \mathrm{~cm}$ no interior do quadrante previamente estabelecido. Com esses procedimentos, coletaram-se 40 amostras compostas (5 solos $\mathrm{x} 2$ profundidades $\mathrm{x} 4$ épocas de coleta), as quais foram acondicionadas em sacos plásticos e colocadas em caixas de isopor com gelo para transporte até o laboratório - cuidado importante para as determinações microbiológicas.

No laboratório, parte da amostra foi seca ao ar, moída e passada em peneira de plástico de malha de $2 \mathrm{~mm}$ (TFSA) para as seguintes determinações: umidade de campo (método gravimétrico); análise textural (método da pipeta); capacidade de campo (mesa de tensão); $\mathrm{pH}$ em água; $\mathrm{Al}^{3+}, \mathrm{Ca}^{2+}, \mathrm{Mg}^{2+}, \mathrm{K}^{+} \mathrm{e} \mathrm{Na}^{+}$ trocáveis e acidez potencial não trocável (H) (Embrapa, 1997); P disponível (Olsen \& Sommers, 1982); C orgânico (UFPR, 2003); e N total (Jackson, 1970). Após extração com solução de $\mathrm{HNO}_{3} 0,5 \mathrm{~mol} \mathrm{~L}^{-1}$ fervente (Knudsen et al., 1986; Martins et al., 2004) e com $\mathrm{HF}$ e $\mathrm{HNO}_{3}$ concentrados e $\mathrm{H}_{2} \mathrm{O}_{2} 30 \%$ (v/v) (teores totais) (Lim \& Jackson, 1986; Melo et al., 2002), os teores de $\mathrm{Pb}$ e $\mathrm{Zn}$ foram determinados por espectroscopia de emissão atômica com plasma acoplado indutivamente (ICP-AES). Os resultados das análises físicas, químicas e os teores de $\mathrm{Pb}$ e $\mathrm{Zn}$ são apresentados nos quadros 2, 3 e 4 , respectivamente.

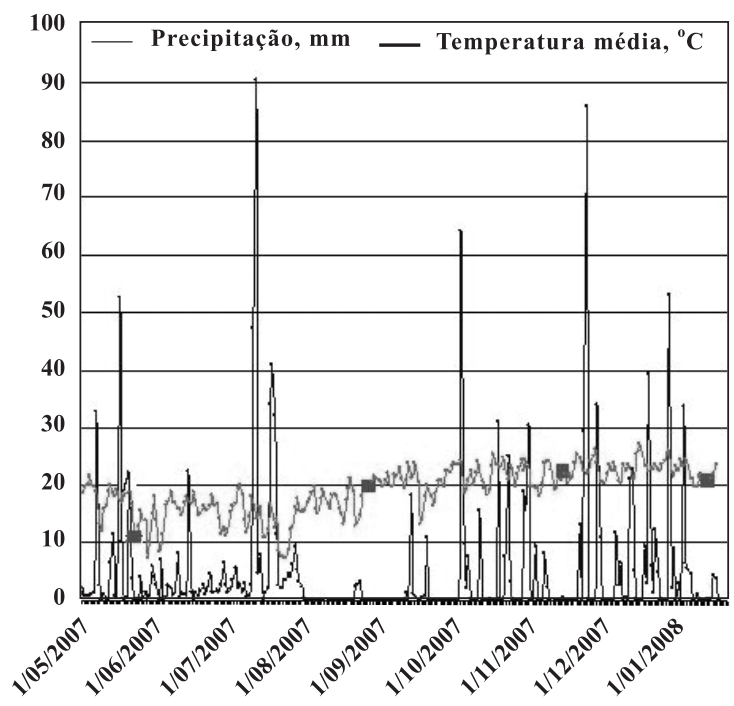

Figura 2. Precipitação pluvial e temperatura média na região de Adrianópolis durante a época de amostragem dos solos. Os pontos no gráfico de temperatura representam os dias de coleta, o que evidencia a condição de menor temperatura da região na coleta de maio. Fonte: Dados da Estação Experimental de Cerro Azul (distante, aproximadamente, $35 \mathrm{~km}$ da área de estudo), fornecidos pelo SIMEPAR (PR).
Em estudo de fitoextração (girassol, aveia-preta e grama-batatais) de $\mathrm{Pb}$ e $\mathrm{Zn}$ com amostras de solos retiradas dos mesmos locais do presente estudo, Andrade et al. (2009a,b) observaram que a extração com $\mathrm{HNO}_{3}$ 0,5 mol L-1 fervente foi o método que melhor se correlacionou com a absorção desses metais pelas plantas (coeficientes de correlação entre $0,97^{*}$, $\left.\mathrm{p}<0,05, \mathrm{e} 1,00^{* * *}, \mathrm{p}<0,0001\right)$. Contudo, devido ao alto poder de extração de metais pesados da solução de $\mathrm{HNO}_{3}$ 0,5 mol L-1 (Soon \& Bates, 1982), mesmo com os altos valores dos coeficientes de correlação, os teores de $\mathrm{Pb}$ na parte aérea das plantas representaram apenas cerca de $2 \%$ daqueles obtidos nos solos. Nos trabalhos de Andrade et al. (2009a,b) foram testados outros extratores para avaliar a disponibilidade de $\mathrm{Pb}$ e $\mathrm{Zn}$ às plantas: DTPA-TEA $\mathrm{pH} 7,3 ; \mathrm{Ca}\left(\mathrm{NO}_{3}\right)_{2}$ $0,5 \mathrm{~mol} \mathrm{~L}^{-1} ; \mathrm{HNO}_{3} 1,0$ e $4 \mathrm{~mol} \mathrm{~L}^{-1}$; e água-régia $\left(\mathrm{HNO}_{3} / \mathrm{HCl}\right.$ concentrados - 3:1).

A outra porção da amostra úmida e refrigerada de solo foi passada em peneira de plástico com $2 \mathrm{~mm}$ de malha, procedendo-se à incubação para a contagem da população microbiana, logo após a chegada do campo; essa análise foi realizada apenas para a profundidade de 0 a $5 \mathrm{~cm}$.

Amostras, nas mesmas condições, foram usadas para estimativa da respiração microbiana (RMS) e do carbono de biomassa microbiana do solo (CBMS); entretanto, esses atributos foram determinados para as profundidades de 0 a 5 e de 5 a $10 \mathrm{~cm}$.

Antes da determinação do CBMS a umidade da amostra foi corrigida para $70 \%$ da capacidade de campo (CC) e submetida a um pré-condicionamento no escuro durante sete dias (Grisi, 1995).

\section{Análises microbiológicas}

\section{Contagem da população de bactérias (totais e esporuláveis) e fungos}

A estimativa do número de bactérias totais (BT) e bactérias esporuláveis (BESP) e fungos (FG) foi realizada por meio da contagem do número de unidades formadoras de colônias (UFC), pelo método da inoculação de suspensões diluídas de solo em meios de culturas específicos (Wollum II, 1982). Para reduzir o erro experimental, todas as determinações foram feitas em triplicata. Utilizou-se o meio Thorton para as bactérias totais e esporuláveis (Parkinson et al., 1971) e Martin para os fungos (Menzies, 1965).

Para determinação das bactérias esporuláveis, as soluções diluídas foram aquecidas a $85^{\circ} \mathrm{C}$ por $15 \mathrm{~min}$, em banho-maria, antes da inoculação, fazendo com que houvesse crescimento apenas das bactérias com capacidade de formar esporos (Frighetto \& Valarini, 2000).

O cálculo da população de bactérias (totais e esporuláveis) e fungos foi feito de acordo com a fórmula sugerida por Ribeiro \& Soares (2002). 


\section{Respiração microbiana}

Cerca de $100 \mathrm{~g}$ de solo (base úmida) foram incubados, em quadruplicata, dentro de um recipiente hermeticamente fechado, contendo $20 \mathrm{~mL}$ de solução de $\mathrm{NaOH}$ 0,05 $\mathrm{mol} \mathrm{L}^{-1}$, padronizado, em tubo de ensaio, durante cinco dias à temperatura de $25 \pm 2{ }^{\circ} \mathrm{C}$ no escuro. No sistema hermético, também foi colocado um tubo de ensaio com $10 \mathrm{~mL}$ de água, para manter a umidade do ambiente de reação. Após o período de incubação realizou-se a titulação da amostra, adicionando-se $5 \mathrm{~mL}$ de $\mathrm{BaCl}_{2} 0,5 \mathrm{~mol} \mathrm{~L}^{-1}$, que reagiu com o $\mathrm{CO}_{2}$ liberado da respiração microbiana, formando precipitado $\mathrm{BaCO}_{3}$. O restante do $\mathrm{NaOH}$ foi quantificado pela reação com $\mathrm{HCl} 0,05 \mathrm{~mol} \mathrm{~L}^{-1}$ na presença de fenoftaleína $0,1 \%$ (Anderson, 1982). O mesmo procedimento foi realizado com frasco sem amostra de solo (branco). A taxa de $\mathrm{CO}_{2}$ capturado foi calculada segundo a expressão descrita por Anderson (1982) e Heinemeyer et al. (1989).

\section{Biomassa microbiana}

A determinação do CBMS foi feita por meio do método da fumigação $\left(\mathrm{CHCl}_{3}\right.$ concentrado e livre de etanol)/extração ( $\mathrm{K}_{2} \mathrm{SO}_{4} 0,5 \mathrm{~mol} \mathrm{~L}{ }^{-1}, \mathrm{pH}$ ajustado entre $6,5$ e 6,8$)$ e oxidação do $\mathrm{C}$ orgânico pelo dicromato de $\mathrm{K} 66,7 \mathrm{mmol} \mathrm{L}-1,10 \mathrm{~mL}$ de $\mathrm{H}_{2} \mathrm{SO}_{4}$ e $5 \mathrm{~mL}$ de $\mathrm{H}_{3} \mathrm{PO}_{4}$ concentrados e titulação com $\mathrm{Fe}\left(\mathrm{NH}_{4}\right)_{2}\left(\mathrm{SO}_{4}\right)_{2}$ $33 \mathrm{mmol} \mathrm{L}^{-1}$ padronizado, na presença de difenilamina 1 \% (Vance et al., 1987; Tate et al., 1988). A avaliação do CBMS foi realizada em triplicata, e para cada 10 amostras fez-se também uma prova em branco. O CBMS foi calculado segundo Tate et al. (1988).

\section{Análise estatística}

O tratamento estatístico dos dados foi realizado por meio de três métodos: diferenciação dos solos por meio da análise de componentes principais (ACP); obtenção de índice de qualidade ambiental relativo aos atributos microbiológicos (IQAMi); e análise de correlação simples (Pearson) entre os atributos microbiológicos e as propriedades físicas (Quadro 2) e químicas (Quadro 3) e os teores de Pb e Zn (Quadro 4) dos solos.

O primeiro método consistiu de análise por componentes principais (ACP), com o objetivo de verificar quais atributos microbiológicos do solo poderiam ser utilizados para diferenciar ou para indicar

Quadro 2. Propriedades físicas das camadas de 0 a 5 e de 5 a $10 \mathrm{~cm}$ dos solos

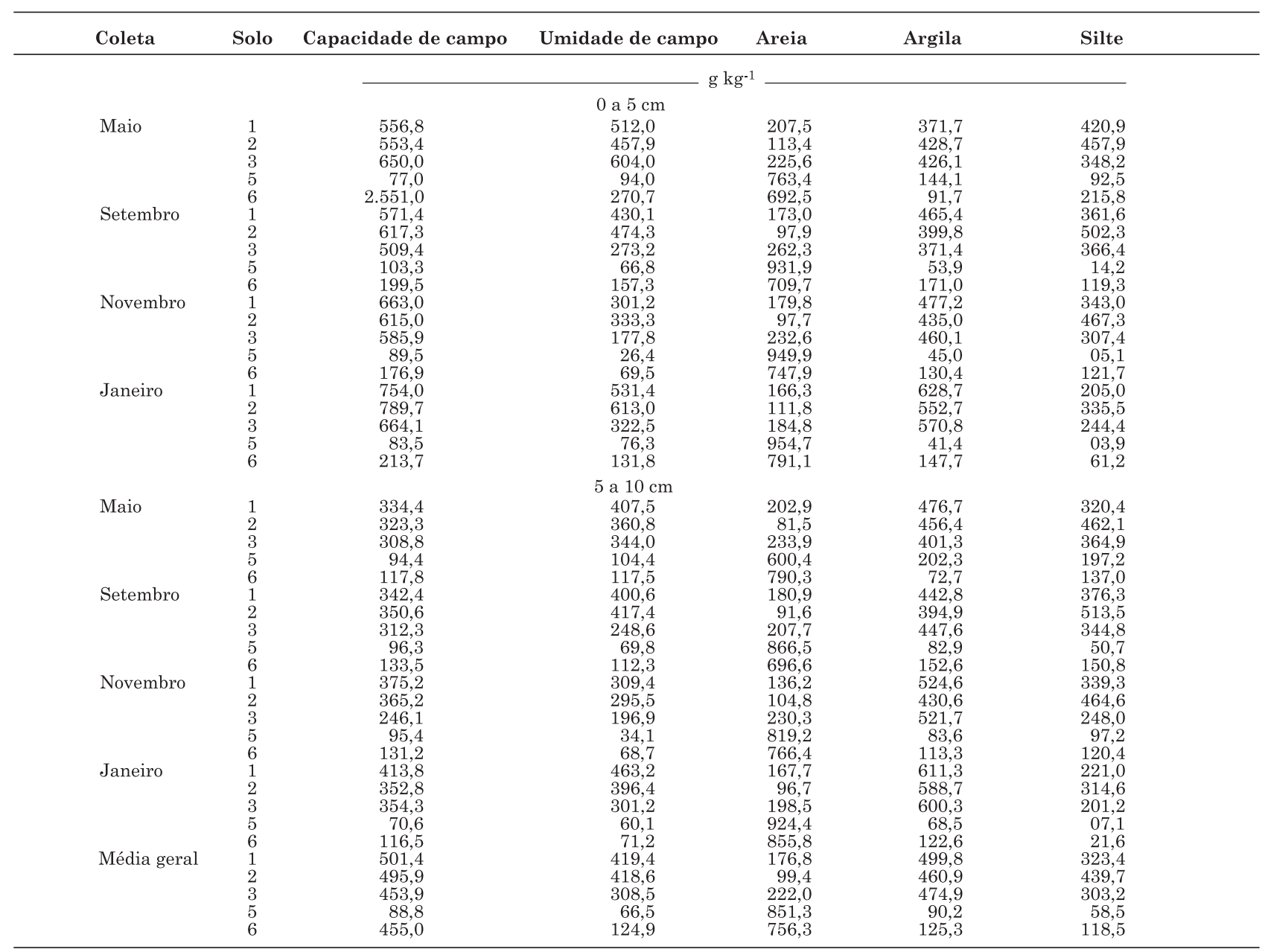


Quadro 3. Propriedades químicas das camadas de 0 a 5 e de 5 a $10 \mathrm{~cm}$ dos solos

\begin{tabular}{|c|c|c|c|c|c|c|c|c|c|c|c|c|c|c|c|}
\hline Coleta & Solo & $\mathbf{p H}$ & $\mathbf{H}$ & $\mathrm{Al}^{3+}$ & $\mathrm{Na}^{+}$ & $\mathbf{K}^{+}$ & $\mathrm{Ca}^{2+}$ & $\mathrm{Mg}^{2+}$ & $\mathbf{S}$ & $\begin{array}{l}\text { CTC } \\
\text { total }\end{array}$ & V & $\mathrm{CO}$ & $\mathbf{N}$ & $\begin{array}{c}\text { Relação } \\
\text { C/N }\end{array}$ & $\mathbf{P}$ \\
\hline & & & \multirow{2}{*}{\multicolumn{8}{|c|}{$\mathrm{cmol}_{\mathrm{c}} \mathrm{kg}^{-1}$}} & $\%$ & \multirow{2}{*}{\multicolumn{2}{|c|}{$-\mathrm{g} \mathrm{kg}^{-1}-$}} & & $\mathrm{mg} \mathrm{kg}^{-1}$ \\
\hline & & & & & & & & & & & & & & & \\
\hline \multirow[t]{5}{*}{ Maio } & 1 & 6,5 & 4,0 & 0,0 & 0,08 & 0,34 & 17,4 & 6,3 & 24,1 & 28,1 & 85,8 & 50,3 & 6,9 & 7,2 & 5,6 \\
\hline & 2 & 6,3 & 5,2 & 0,0 & 0,07 & 0,33 & 20,3 & 4,2 & 24,9 & 30,1 & 82,7 & 41,7 & 5,1 & 8,1 & 3,9 \\
\hline & 3 & 6,9 & 2,4 & 0,0 & 0,13 & 1,68 & 23,7 & 4,2 & 29,7 & 32,1 & 92,5 & 74,7 & 8,7 & 8,6 & 13,7 \\
\hline & 5 & 7,7 & 0,0 & 0,0 & 0,40 & 0,83 & 1,8 & 0,3 & 3,3 & 3,3 & 100,0 & 11,5 & 0,1 & 104,6 & 5,9 \\
\hline & 6 & 5,3 & 5,2 & 0,0 & 0,06 & 0,32 & 3,6 & 1,2 & 5,2 & 10,4 & 49,8 & 30,8 & 2,0 & 15,8 & 4,3 \\
\hline \multirow[t]{5}{*}{ Setembro } & 1 & 6,3 & 5,2 & 0,0 & 0,05 & 0,48 & 13,9 & 5,0 & 19,4 & 24,6 & 78,9 & 58,2 & 7,0 & 8,4 & 4,4 \\
\hline & 2 & 7,0 & 0,8 & 0,0 & 0,07 & 0,28 & 23,7 & 2,5 & 26,6 & 27,4 & 97,1 & 51,7 & 5,3 & 9,8 & 3,3 \\
\hline & 3 & 7,0 & 2,0 & 0,0 & 0,07 & 0,73 & 19,3 & 2,0 & 22,1 & 24,1 & 91,7 & 50,0 & 5,9 & 8,5 & 20,6 \\
\hline & 5 & 7,8 & 0,0 & 0,0 & 0,23 & 0,45 & 3,3 & 0,4 & 4,4 & 4,4 & 100,0 & 26,6 & 0,9 & 29,0 & 6,5 \\
\hline & 6 & 4,8 & 3,3 & 0,3 & 0,02 & 0,26 & 1,3 & 0,1 & 1,7 & 5,3 & 32,2 & 19,6 & 1,7 & 11,4 & 4,8 \\
\hline \multirow[t]{5}{*}{ Novembro } & 1 & 5,7 & 10,0 & 0,0 & 0,07 & 0,45 & 17,2 & 5,4 & 23,1 & 33,1 & 69,8 & 53,5 & 7,2 & 7,4 & 4,6 \\
\hline & 2 & 6,9 & 2,0 & 0,0 & 0,07 & 0,18 & 24,4 & 6,1 & 30,7 & 32,7 & 93,9 & 50,3 & 6,7 & 7,6 & 5,7 \\
\hline & 3 & 6,8 & 2,4 & 0,0 & 0,06 & 1,08 & 20,5 & 2,2 & 23,8 & 26,2 & 90,9 & 49,5 & 6,2 & 8,0 & 17,1 \\
\hline & 5 & 7,8 & 0,0 & 0,0 & 0,27 & 0,51 & 3,6 & 0,4 & 4,7 & 4,7 & 100,0 & 13,8 & 0,3 & 40,2 & 7,7 \\
\hline & 6 & 5,1 & 2,2 & 0,2 & 0,02 & 0,27 & 0,7 & 0,7 & 1,7 & 4,1 & 40,9 & 16,1 & 1,2 & 14,0 & 3,8 \\
\hline \multirow[t]{6}{*}{ Janeiro } & 1 & 6,7 & 2,4 & 0,0 & 0,08 & 0,45 & 21,0 & 5,6 & 27,1 & 29,5 & 91,9 & 81,4 & 8,2 & 10,0 & 3,8 \\
\hline & 2 & 7,2 & 0,8 & 0,0 & 0,08 & 0,23 & 22,4 & 6,9 & 29,6 & 30,4 & 97,4 & 42,1 & 7,1 & 5,9 & 7,1 \\
\hline & 3 & 6,4 & 4,8 & 0,0 & 0,08 & 0,92 & 50,6 & 4,3 & 55,9 & 60,7 & 92,1 & 57,7 & 6,7 & 8,7 & 15,9 \\
\hline & 5 & 7,5 & 0,0 & 0,0 & 0,34 & 0,71 & 2,3 & 0,3 & 3,6 & 3,6 & 100,0 & 19,4 & 0,6 & 33,8 & 5,2 \\
\hline & 6 & 5,5 & 3,1 & 0,1 & 0,02 & 0,33 & 2,6 & 0,7 & 3,6 & 6,8 & 53,0 & 26,8 & 0,6 & 46,6 & 3,1 \\
\hline & \multicolumn{15}{|c|}{5 a $10 \mathrm{~cm}$} \\
\hline \multirow[t]{5}{*}{ Maio } & 1 & 5,7 & 3,6 & 0,0 & 0,07 & 0,17 & 13,1 & 5,1 & 18,4 & 22,0 & 83,7 & 34,7 & 5,1 & 6,9 & 2,6 \\
\hline & 2 & 6,5 & 4,4 & 0,0 & 0,7 & 0,19 & 21,5 & 3,9 & 26,2 & 30,7 & 85,6 & 29,3 & 5,5 & 5,3 & 2,7 \\
\hline & 3 & 6,3 & 4,0 & 0,0 & 0,27 & 1,08 & 18,6 & 2,6 & 22,5 & 26,5 & 84,9 & 36,4 & 4,6 & 8,0 & 19,2 \\
\hline & 5 & 8,1 & 0,0 & 0,0 & 0,30 & 0,5 & 4,5 & 0,4 & 5,7 & 5,7 & 100,0 & 12,3 & 0,5 & 26,8 & 5,8 \\
\hline & 6 & 6,1 & 4,8 & 0,0 & 0,03 & 0,17 & 0,4 & 0,1 & 0,7 & 5,5 & 12,6 & 8,9 & 0,8 & 11,2 & 1,6 \\
\hline \multirow[t]{5}{*}{ Setembro } & 1 & 5,6 & 6,4 & 0,0 & 0,05 & 0,23 & 14,4 & 5,4 & 20,0 & 26,4 & 75,8 & 46,2 & 5,2 & 9,0 & 2,6 \\
\hline & 2 & 7,3 & 0,8 & 0,0 & 0,06 & 0,15 & 27,9 & 2,2 & 30,3 & 31,1 & 97,4 & 46,3 & 6,2 & 7,5 & 3,6 \\
\hline & 3 & 6,7 & 2,4 & 0,0 & 0,06 & 0,47 & 20,0 & 1,2 & 21,7 & 24,1 & 90,1 & 39,1 & 3,9 & 10,1 & 19,9 \\
\hline & 5 & 7,9 & 0,0 & 0,0 & 0,24 & 0,45 & 4,7 & 0,3 & 5,7 & 5,7 & 100,0 & 18,7 & 0,5 & 40,9 & 6,1 \\
\hline & 6 & 4,7 & 2,2 & 1,0 & 0,01 & 0,13 & 0,5 & 3,2 & 3,8 & 7,0 & 54,5 & 6,2 & 1,2 & 5,4 & 2,4 \\
\hline \multirow[t]{5}{*}{ Novembro } & 1 & 5,5 & 8,0 & 0,0 & 0,05 & 0,23 & 16,9 & 5,2 & 22,4 & 30,4 & 73,7 & 45,4 & 6,9 & 6,6 & 3,8 \\
\hline & 2 & 7,0 & 2,0 & 0,0 & 0,06 & 0,13 & 26,6 & 5,0 & 31,8 & 33,8 & 94,1 & 43,6 & 5,1 & 8,6 & 4,1 \\
\hline & 3 & 6,8 & 2,0 & 0,0 & 0,06 & 0,53 & 21,7 & 0,9 & 23,2 & 25,2 & 92,1 & 32,6 & 4,6 & 7,1 & 9,1 \\
\hline & 5 & 8,2 & 0,0 & 0,0 & 0,23 & 0,42 & 4,2 & 0,4 & 5,2 & 5,2 & 100,0 & 15,2 & 0,1 & 138,5 & 7,2 \\
\hline & 6 & 4,9 & 3,7 & 0,3 & 0,01 & 0,22 & 0,5 & 0,2 & 1,0 & 5,0 & 19,1 & 8,6 & 0,8 & 10,7 & 2,6 \\
\hline \multirow[t]{5}{*}{ Janeiro } & 1 & 6,0 & 5,6 & 0,0 & 0,06 & 0,24 & 20,5 & 4,8 & 25,6 & 31,2 & 82,0 & 58,8 & 7,1 & 8,3 & 3,0 \\
\hline & 2 & 7,3 & 0,4 & 0,0 & 0,07 & 0,12 & 25,0 & 3,7 & 28,9 & 29,3 & 98,6 & 42,4 & 4,9 & 8,6 & 3,8 \\
\hline & 3 & 6,1 & 4,4 & 0,0 & 0,05 & 0,7 & 18,4 & 1,5 & 20,7 & 25,1 & 82,5 & 41,0 & 4,9 & 8,3 & 21,4 \\
\hline & 5 & 7,7 & 0,0 & 0,0 & 0,31 & 0,56 & 1,7 & 0,2 & 2,7 & 2,7 & 100,0 & 22,8 & 0,2 & 99,1 & 6,2 \\
\hline & 6 & 5,6 & 1,9 & 0,1 & 0,01 & 0,2 & 0,6 & 0,0 & 0,8 & 2,8 & 29,6 & 12,4 & 0,1 & 108,1 & 2,0 \\
\hline \multirow{5}{*}{ Média geral } & 1 & 6,0 & 5,6 & 0,0 & 0,08 & 0,33 & 16,8 & 5,4 & 22,5 & 28,2 & 80,2 & 53,6 & 6,7 & 8,0 & 3,8 \\
\hline & 2 & 6,9 & 2,1 & 0,0 & 0,08 & 0,20 & 24,0 & 4,3 & 28,6 & 30,7 & 93,4 & 43,4 & 5,7 & 7,7 & 4,3 \\
\hline & 3 & 6,6 & 3,0 & 0,0 & 0,11 & 0,90 & 24,1 & 2,4 & 27,5 & 30,5 & 89,6 & 47,6 & 5,7 & 8,4 & 17,1 \\
\hline & 5 & 7,8 & 0,0 & 0,0 & 0,29 & 0,55 & 3,3 & 0,3 & 4,4 & 4,4 & 100,0 & 17,5 & 0,4 & 64,1 & 6,3 \\
\hline & 6 & 5,3 & 3,3 & 0,3 & 0,02 & 0,24 & 1,3 & 0,8 & 2,3 & 5,9 & 36,5 & 16,2 & 1,0 & 27,9 & 3,1 \\
\hline
\end{tabular}

similaridades entre as amostras coletadas em diferentes locais, profundidades e épocas de coletas. O conjunto de métodos analíticos, cujos resultados configuram-se em uma matriz multidimensional, foi submetido à análise de ACP, que consiste de um conjunto de ferramentas estatísticas orientadas a comprimir a matriz original, sem perda de informação relevante (Geladi et al., 1989).

No segundo método também se fez uso de componentes principais, porém essa análise serviu para selecionar variáveis que representassem $99 \%$ da variação total dos dados microbiológicos, separadamente para cada profundidade. A partir das variáveis selecionadas fez-se a estandardização dos dados (Z):

$$
Z=\frac{X-\mu}{\sigma}
$$

em que $X$ é o valor do parâmetro; $\mu$, a média geral dos dados; e $\sigma$, o desvio-padrão.

Posteriormente, realizou-se a multiplicação de cada dado estandardizado pelo peso que a variável de origem 
representava na primeira componente principal. $\mathrm{O}$ IQAMi foi obtido pela soma de todas as variáveis microbiológicas, o que gerou um único valor por solo e época de amostragem. Gerou-se, então, uma matriz de correlação dos dados microbiológicos com as variáveis independentes estudadas (Quadros 2, 3 e 4) e, daí, selecionaram-se as variáveis independentes que apresentavam correlação maior que 0,5. Em seguida, foram construídos gráficos de regressão linear das variáveis independentes com os índices de qualidade ambiental microbiológica (IQAMi).

\section{RESULTADOS E DISCUSSÃO}

\section{Indicadores microbiológicos na profundidade de 0 a $5 \mathrm{~cm}$}

O grupo das bactérias totais (BT) foi o mais abundante na contagem microbiana (Quadro 5), com número médio de propágulos viáveis variando entre $10^{4}$ e $10^{6} \mathrm{UFC} \mathrm{g}^{-1}$ de solo seco, seguidas pelas bactérias esporuláveis (BSEP) e fungos (FGS), os quais apresentaram variação entre $10^{3}$ e $10^{5} \mathrm{FC}^{-1}$.

Quadro 4. Teores de $\mathrm{Pb}$ e $\mathrm{Zn}$ totais (HF) e extraídos com $\mathrm{HNO}_{3}$ nas camadas de 0 a 5 e de 5 a $10 \mathrm{~cm}_{\text {dos solos }}^{(1)}$

\begin{tabular}{|c|c|c|c|c|c|c|}
\hline \multirow{2}{*}{ Coleta } & \multirow{2}{*}{ Solo } & \multicolumn{2}{|c|}{ 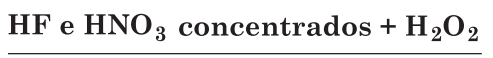 } & \multicolumn{3}{|c|}{$\mathrm{HNO}_{3} \quad 0,5 \mathrm{~mol} \mathrm{~L}^{-1}$} \\
\hline & & $\mathbf{P b}$ & $\mathrm{Zn}$ & & $\mathrm{Pb}$ & $\mathrm{Zn}$ \\
\hline & & & & $\mathrm{mg} \mathrm{kg}^{-1}$ & & \\
\hline & & & & 0 a $5 \mathrm{~cm}$ & & \\
\hline \multirow[t]{5}{*}{ Maio } & 1 & 464,5 & 293,7 & & 420,6 & 81,9 \\
\hline & 2 & 5761,1 & 317,2 & & 4361,1 & 242,2 \\
\hline & 3 & 14179,7 & 1196,3 & & 9467,2 & 985,2 \\
\hline & 5 & 17261,5 & 23434,6 & & 2410,5 & 2573,7 \\
\hline & 6 & 734,6 & nd & & 472,5 & nd \\
\hline \multirow[t]{5}{*}{ Setembro } & 1 & 577,9 & 394,1 & & 520,9 & 93,2 \\
\hline & 2 & 5322,2 & 424,1 & & 4779,3 & 282,3 \\
\hline & 3 & 15248,3 & 1160,8 & & 14457,9 & 1071,4 \\
\hline & 5 & 19237,5 & 23337,3 & & 2499,0 & 2528,5 \\
\hline & 6 & 1301,9 & nd & & 859,1 & nd \\
\hline \multirow[t]{5}{*}{ Novembro } & 1 & 813,2 & 211,8 & & 677,9 & 108,5 \\
\hline & 2 & 6269,7 & 388,9 & & 4153,5 & 228,9 \\
\hline & 3 & 14863,0 & 1222,4 & & 12796,1 & 962,5 \\
\hline & 5 & 22109,3 & 33371,9 & & 2849,5 & 2535,9 \\
\hline & 6 & 788,3 & 40,5 & & 698,7 & 18,8 \\
\hline \multirow[t]{6}{*}{ Janeiro } & 1 & 764,6 & 105,2 & & 362,7 & 70,2 \\
\hline & 2 & 10205,8 & 796,8 & & 2714,6 & 263,9 \\
\hline & 3 & 17460,9 & 1668,2 & & 12007,5 & 808,9 \\
\hline & 5 & 25190,8 & 54238,4 & & 1910,9 & 2527,0 \\
\hline & 6 & 560,1 & nd & & 493,6 & nd \\
\hline & & & & 5 a $10 \mathrm{~cm}$ & & \\
\hline \multirow[t]{5}{*}{ Maio } & 1 & 475,4 & 99,9 & & 290,7 & 68,0 \\
\hline & 2 & 4173,4 & 190,2 & & 3101,7 & 117,1 \\
\hline & 3 & 17203,1 & 1078,9 & & 15370,5 & 975,1 \\
\hline & 5 & 10345,6 & 21539,1 & & 1346,5 & 1995,6 \\
\hline & 6 & 903,9 & nd & & 534,9 & nd \\
\hline \multirow[t]{5}{*}{ Setembro } & 1 & 499,5 & 189,8 & & 445,2 & 73,2 \\
\hline & 2 & 4269,8 & 268,9 & & 4083,9 & 194,7 \\
\hline & 3 & 15406,5 & 1058,9 & & 15230,2 & 999,2 \\
\hline & 5 & 18165,8 & 23482,9 & & 2868,5 & 2442,7 \\
\hline & 6 & 871,1 & nd & & 552,8 & nd \\
\hline \multirow[t]{5}{*}{ Novembro } & 1 & 1283,9 & 3065,3 & & 723,9 & 94,2 \\
\hline & 2 & 5497,5 & 334,5 & & 4262,8 & 162,4 \\
\hline & 3 & 8996,7 & 925,4 & & 8176,9 & 827,1 \\
\hline & 5 & 17887,9 & 34521,8 & & 2043,4 & 2361,9 \\
\hline & 6 & 1251,2 & 79,1 & & 823,6 & 25,3 \\
\hline \multirow[t]{5}{*}{ Janeiro } & 1 & 1025,8 & 93,0 & & 647,0 & 18,7 \\
\hline & 2 & 5885,9 & 495,4 & & 3883,2 & 150,0 \\
\hline & 3 & 14096,3 & 975,7 & & 8438,1 & 745,7 \\
\hline & 5 & 25930,3 & 51601,2 & & 1969,9 & 2391,8 \\
\hline & 6 & 556,5 & nd & & 540,6 & nd \\
\hline \multirow[t]{5}{*}{ Média geral } & 1 & 738,1 & 556,6 & & 511,1 & 76,0 \\
\hline & 2 & 5923,2 & 402,0 & & 3917,5 & 205,2 \\
\hline & 3 & 14681,8 & 1160,8 & & 11993,1 & 921,9 \\
\hline & 4 & 19516,1 & 33190,9 & & 2237,3 & 2419,6 \\
\hline & 5 & 871,0 & 15,0 & & 622,0 & 5,5 \\
\hline
\end{tabular}

(1) nd: teores abaixo do nível de deteç̧ão do método analítico empregado (ICP-AES). 
Quadro 5. Atributos microbiológicos da camada de 0 a 5 cm dos solos ${ }^{(1)}$

\begin{tabular}{|c|c|c|c|c|c|c|c|c|c|c|c|c|}
\hline \multirow{2}{*}{ Coleta } & \multirow{2}{*}{ Solo } & \multicolumn{5}{|c|}{ Contagem microbiana } & \multicolumn{2}{|c|}{ Respiração microbiana } & \multirow{2}{*}{ CBMS } & \multirow{2}{*}{ CBMS } & \multirow{2}{*}{$\mathrm{qCO}_{2} \mathrm{a}$} & \multirow{2}{*}{$\mathrm{qCO}_{2} \mathrm{~b}$} \\
\hline & & BT & BESP & FGS & BESP & FG/BT & RMS1 & RMS2 & & & & \\
\hline & & $-\mathrm{L}$ & $\mathrm{FC} \mathrm{g}^{-1} \mathrm{~S}$ & $S-$ & $\%$ & & $\mathrm{mg} \mathrm{C}-\mathrm{CC}$ & $\mathrm{kg}^{-1} \mathrm{SS} \mathrm{h}^{-1}$ & $\mathrm{mg} \mathrm{C} \mathrm{kg}{ }^{-1} \mathrm{SS}$ & $\%$ & & \\
\hline Maio & $\begin{array}{l}1 \\
2 \\
3 \\
5 \\
6\end{array}$ & $\begin{array}{l}9,52 \\
0,80 \\
2,70 \\
0,76 \\
6,66\end{array}$ & $\begin{array}{l}2,78 \\
0,74 \\
8,94 \\
2,16 \\
4,64\end{array}$ & $\begin{array}{l}0,89 \\
0,05 \\
0,24 \\
0,24 \\
1,70\end{array}$ & $\begin{array}{r}2,92 \\
9,25 \\
33,11 \\
28,42 \\
6,97\end{array}$ & $\begin{array}{l}0,009 \\
0,006 \\
0,009 \\
0,032 \\
0,026\end{array}$ & $\begin{array}{l}0,79 \\
0,71 \\
1,31 \\
0,13 \\
0,51\end{array}$ & $\begin{array}{l}0,58 \\
0,46 \\
0,78 \\
0,14 \\
0,34\end{array}$ & $\begin{array}{l}\text { nd } \\
\text { nd } \\
\text { nd } \\
\text { nd } \\
\text { nd }\end{array}$ & $\begin{array}{l}\text { nd } \\
\text { nd } \\
\text { nd } \\
\text { nd } \\
\text { nd }\end{array}$ & $\begin{array}{l}\text { nd } \\
\text { nd } \\
\text { nd } \\
\text { nd } \\
\text { nd }\end{array}$ & $\begin{array}{l}\text { nd } \\
\text { nd } \\
\text { nd } \\
\text { nd } \\
\text { nd }\end{array}$ \\
\hline Setembro & $\begin{array}{l}1 \\
2 \\
3 \\
5 \\
6\end{array}$ & $\begin{array}{r}15,86 \\
6,79 \\
3,58 \\
0,91 \\
0,42\end{array}$ & $\begin{array}{l}1,17 \\
1,06 \\
0,20 \\
1,60 \\
0,02\end{array}$ & $\begin{array}{l}0,69 \\
1,26 \\
1,53 \\
0,29 \\
1,30\end{array}$ & $\begin{array}{r}0,74 \\
1,56 \\
0,56 \\
17,58 \\
0,48\end{array}$ & $\begin{array}{l}0,004 \\
0,019 \\
0,043 \\
0,032 \\
0,310\end{array}$ & $\begin{array}{l}1,49 \\
1,29 \\
0,71 \\
0,17 \\
0,16\end{array}$ & $\begin{array}{l}1,19 \\
1,05 \\
0,55 \\
0,14 \\
0,13\end{array}$ & $\begin{array}{r}571,6 \\
426,6 \\
366,6 \\
257,2 \\
86,9\end{array}$ & $\begin{array}{l}0,98 \\
0,83 \\
0,73 \\
0,97 \\
0,44\end{array}$ & $\begin{array}{l}2,60 \\
3,03 \\
1,94 \\
0,67 \\
1,84\end{array}$ & $\begin{array}{l}2,08 \\
2,46 \\
1,49 \\
0,53 \\
1,54\end{array}$ \\
\hline Novembro & $\begin{array}{l}1 \\
2 \\
3 \\
5 \\
6\end{array}$ & $\begin{array}{l}1,97 \\
2,07 \\
0,27 \\
1,51 \\
0,88\end{array}$ & $\begin{array}{l}1,07 \\
0,66 \\
0,34 \\
1,08 \\
0,06\end{array}$ & $\begin{array}{l}0,73 \\
2,91 \\
0,34 \\
0,52 \\
2,75\end{array}$ & $\begin{array}{r}5,43 \\
3,18 \\
12,39 \\
7,16 \\
0,65\end{array}$ & $\begin{array}{l}0,037 \\
0,141 \\
0,124 \\
0,034 \\
0,314\end{array}$ & $\begin{array}{l}1,11 \\
1,37 \\
0,37 \\
0,07 \\
0,12\end{array}$ & $\begin{array}{l}0,84 \\
1,06 \\
0,31 \\
0,07 \\
0,12\end{array}$ & $\begin{array}{l}873,0 \\
803,0 \\
296,5 \\
383,0 \\
181,2\end{array}$ & $\begin{array}{l}1,63 \\
1,60 \\
0,60 \\
2,77 \\
1,12\end{array}$ & $\begin{array}{l}1,27 \\
1,70 \\
1,25 \\
0,18 \\
0,67\end{array}$ & $\begin{array}{l}0,96 \\
1,32 \\
1,06 \\
0,17 \\
0,67\end{array}$ \\
\hline Janeiro & $\begin{array}{l}1 \\
2 \\
3 \\
5 \\
6\end{array}$ & $\begin{array}{l}34,53 \\
56,72 \\
37,37 \\
10,30 \\
23,96\end{array}$ & $\begin{array}{r}64,94 \\
77,05 \\
15,08 \\
14,60 \\
9,54\end{array}$ & $\begin{array}{r}23,54 \\
10,70 \\
9,52 \\
1,15 \\
8,72\end{array}$ & $\begin{array}{r}18,81 \\
13,58 \\
4,03 \\
14,17 \\
3,98\end{array}$ & $\begin{array}{l}0,068 \\
0,019 \\
0,025 \\
0,011 \\
0,036\end{array}$ & $\begin{array}{l}1,67 \\
1,84 \\
0,75 \\
0,29 \\
0,36\end{array}$ & $\begin{array}{l}1,44 \\
1,64 \\
0,61 \\
0,25 \\
0,31\end{array}$ & $\begin{array}{r}1158,4 \\
877,1 \\
690,4 \\
903,2 \\
521,6\end{array}$ & $\begin{array}{l}1,42 \\
2,08 \\
1,20 \\
4,65 \\
1,95\end{array}$ & $\begin{array}{l}1,44 \\
2,10 \\
1,08 \\
0,32 \\
0,69\end{array}$ & $\begin{array}{l}1,24 \\
1,87 \\
0,88 \\
0,28 \\
0,59\end{array}$ \\
\hline
\end{tabular}

(1) BT: bactérias totais (valores de unidades formadoras de colônia elevados a 105); BTESP: bactérias esporuláveis (valores de unidades formadoras de colônia elevados a 104); BESP\%: percentagem de bactérias esporuláveis em relação à BT; FG/BT: relação entre fungos e bactérias; FGS: fungos (valores de unidades formadoras de colônia elevados a $10^{4}$ ); RMS: respiração microbiana do solo: 1 - durante o período de 5 dias, 2 - durante o período de 10 dias; CBMS: carbono de biomassa microbiana do solo; CBMS\%: percentagem de carbono de biomassa microbiana em relação ao carbono orgânico total do solo; $\mathrm{qCO}_{2} \mathrm{a}$ : quociente metabólico 1 período de 5 dias; $\mathrm{qCO}_{2}$ b: quociente metabólico 2 - período de 10 dias. SS: solo seco. nd: valores não determinados por problemas analíticos com as amostras na coleta do mês de maio.

Com relação à flutuação da população microbiana, nota-se que o mês de janeiro (coleta de verão) apresentou os maiores valores para os três tipos de microrganismos (Quadro 5). Comparando-se maio e setembro, o primeiro mês, de modo geral, mostrou resultados inferiores, sobretudo em função da menor temperatura (Figura 1).

Uma evidência da complexidade na definição da população microbiana do solo - em que outros fatores podem atenuar os efeitos deletérios dos metais pesados - é o comportamento do solo 3. Apesar de possuir os maiores teores de $\mathrm{Pb}$ extraídos com $\mathrm{HNO}_{3}$ 0,5 mol L-1 (Quadro 4), esse solo permaneceu, em relação aos demais, em posição intermediária de população microbiana (Quadro 5), devido às suas características químicas mais favoráveis (Quadro 3): altos valores de CTC, V \% e altos teores de $\mathrm{Ca}^{2+}, \mathrm{Mg}^{2+}$, C orgânico, $\mathrm{Ne}$, principalmente, $\mathrm{K}^{+}$e P. Segundo Biderbeck et al. (1984), o P, assim como o N, pode oferecer melhor condição de sobrevivência aos microrganismos heterotróficos, pois tem efeito estimulador na taxa de decomposição de resíduos. A maior qualidade física e química do solo 3 ficou demonstrada na análise de componentes principais (ACP) no trabalho de Barros (2008).

As mesmas condições que favoreceram a população de BT também foram importantes para o crescimento de FGS e BTESP (coeficientes de correlação (r) entre BT e FGS e BT e BESP $=0,75^{* * *}$ e $0,86^{* * *}$, respectivamente).

Segundo Mergeay (1995), o acúmulo de metais pesados muda a relação FGS/BT, favorecendo os fungos, que são mais resistentes à toxidez desses elementos. Contudo, no presente estudo (Quadro 5) esse atributo não foi um bom bioindicador, uma vez que os coeficientes de correlação com os teores de metais pesados foram baixos e não significativos (Quadro 6). Os fungos são mais adaptados a $\mathrm{pH}$ menores que 5,0, e as bactérias, a pH entre 6 e 8 (Moreira \& Siqueira, 2002). Neste estudo, os valores de $\mathrm{pH}$ da camada de 0 a $5 \mathrm{~cm}$, embora na maioria próximos à neutralidade, variaram de 5,3 a 7,8 (Quadro 3). A relação FGS/BT, possivelmente, seria mais sensível à contaminação com metais pesados sob condições químicas similares dos solos.

Os coeficientes de correlação entre a população microbiana e os teores de $\mathrm{Pb}$ totais e extraídos com $\mathrm{HNO}_{3}$, em todas as coletas, foram baixos e não significativos (Quadro 6).

Quando se consideram apenas os meses de coleta com menor temperatura (Figura 1), as correlações foram mais expressivas: (1) coleta em maio e setembro (10 observações): $\mathrm{Pb}$ total e BTESP $=0,67^{*}$; e (2) coleta apenas em maio (cinco observações): $\mathrm{Pb}$ total e $\mathrm{BT}=$ $-0,77, \mathrm{~Pb}$ total e FGS $=-0,70, \mathrm{~Pb}$ total e BTESP $=$ 
Quadro 6. Correlação entre as variáveis microbiológicas com atributos físicos e químicos na profundidade de 0 a 5 cm$^{(1)}$

\begin{tabular}{|c|c|c|c|c|c|c|c|c|c|c|c|}
\hline & BT & BTESP & FGS & BESP\% & FG/BT & RMS1 & RMS2 & CBMS & CBMS\% & $\mathrm{qCO} 2 \mathrm{a}$ & $\mathrm{qCO} 2 \mathrm{~b}$ \\
\hline Pb Total & $-0,07$ & $-0,07$ & $-0,27$ & 0,40 & $-0,39$ & $-0,40$ & $-0,39$ & $-0,05$ & $0,48^{\circ}$ & $-0,47^{\circ}$ & $-0,48^{\circ}$ \\
\hline Zn Total & $-0,20$ & $-0,09$ & $-0,27$ & 0,43 & $-0,29$ & $-0,45$ & $-0,44$ & 0,08 & $0,80^{* * * *}$ & $-0,60^{*}$ & $-0,61^{*}$ \\
\hline $\mathrm{Pb} \mathrm{HNO}_{3}$ & $-0,04$ & $-0,18$ & $-0,14$ & $-0,12$ & $-0,15$ & $-0,09$ & $-0,11$ & $-0,20$ & $-0,31$ & 0,12 & 0,09 \\
\hline $\mathrm{Zn} \mathrm{HNO}_{3}$ & $-0,27$ & $-0,19$ & $-0,35$ & $0,46^{\circ}$ & $-0,36$ & $-0,52^{*}$ & $-0,51^{\circ}$ & $-0,12$ & $0,51^{*}$ & $-0,58^{*}$ & $-0,60^{*}$ \\
\hline $\mathrm{CC}$ & $0,51^{\circ}$ & $0,48^{\circ}$ & $0,45^{\circ}$ & 0,03 & $-0,28$ & $0,87^{* * *}$ & $0,86^{* * *}$ & $0,55^{*}$ & $-0,35$ & $0,65^{* *}$ & $0,65^{\star *}$ \\
\hline Umidade & $0,65^{* *}$ & $0,64^{* *}$ & $0,54^{*}$ & 0,07 & $-0,33$ & $0,96^{* * *}$ & $0,97^{\text {***}}$ & $0,58^{*}$ & $-0,23$ & $0,77^{\text {***}}$ & $0,78^{* * *}$ \\
\hline Areia & $-0,36$ & $-0,30$ & $-0,29$ & 0,15 & 0,20 & $-0,83^{* * *}$ & $-0,81^{* * *}$ & $-0,42$ & 0,44 & $-0,75^{* * *}$ & $-0,74^{* *}$ \\
\hline Argila & $0,53^{*}$ & $0,48^{\circ}$ & $0,51^{\circ}$ & 0,04 & $-0,24$ & $0,82^{* * *}$ & $0,82^{* * * *}$ & $0,54^{*}$ & $-0,37$ & $0,60^{*}$ & $0,60^{*}$ \\
\hline $\mathrm{pH}$ & 0,09 & 0,21 & $-0,03$ & $0,57^{*}$ & $-0,66^{\star *}$ & 0,14 & 0,15 & 0,26 & 0,40 & $-0,10$ & $-0,11$ \\
\hline $\mathrm{H}^{+}$ & $-0,01$ & $-0,17$ & $-0,01$ & $-0,35$ & 0,01 & 0,23 & 0,18 & 0,21 & $-0,28$ & 0,16 & 0,13 \\
\hline $\mathrm{Ca}^{2+}$ & $0,47^{\circ}$ & 0,25 & 0,34 & $-0,05$ & $-0,33$ & $0,54^{*}$ & $0,53^{*}$ & 0,40 & $-0,27$ & 0,39 & 0,37 \\
\hline $\mathrm{Mg}^{2+}$ & $0,56^{*}$ & $0,54^{*}$ & $0,45^{*}$ & 0,09 & $-0,30$ & $0,92^{* * *}$ & $0,91^{* * * *}$ & $0,70^{* *}$ & $-0,12$ & $0,51^{\circ}$ & $0,51^{\circ}$ \\
\hline $\mathrm{S}$ & $0,50^{\circ}$ & 0,31 & 0,37 & $-0,02$ & $-0,35$ & $0,62^{*}$ & $0,61^{*}$ & $0,47^{\circ}$ & $-0,25$ & 0,42 & 0,40 \\
\hline CTC & $0,47^{\circ}$ & 0,26 & 0,35 & $-0,08$ & $-0,32$ & $0,62^{*}$ & $0,60^{*}$ & $0,47^{\circ}$ & $-0,28$ & 0,42 & 0,40 \\
\hline $\mathrm{V}$ & 0,21 & 0,26 & 0,08 & 0,52 & $-0,74^{\circ}$ & 0,34 & 0,34 & 0,43 & 0,31 & 0,05 & 0,02 \\
\hline $\mathrm{CO}$ & 0,38 & 0,37 & $0,53^{*}$ & 0,13 & $-0,36$ & $0,78^{\star * * *}$ & $0,76^{* * * *}$ & $0,58^{*}$ & $-0,36$ & $0,56^{*}$ & $0,53^{*}$ \\
\hline $\mathrm{N}$ & 0,40 & 0,39 & 0,38 & 0,02 & $-0,26$ & $0,84^{* * *}$ & $0,82^{* * *}$ & $0,54^{*}$ & $-0,37$ & $0,64^{*}$ & $0,62^{*}$ \\
\hline $\mathrm{C} / \mathrm{N}$ & $-0,13$ & $-0,18$ & $-0,10$ & 0,19 & $-0,21$ & $-0,60^{*}$ & $-0,58^{*}$ & $-0,14$ & $0,57^{*}$ & $-0,70^{* *}$ & $-0,70^{* *}$ \\
\hline
\end{tabular}

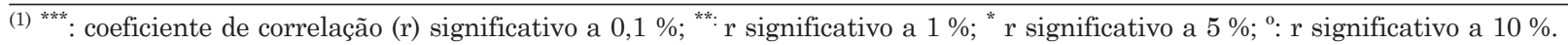

$0,95^{*}, \mathrm{~Pb} \mathrm{HNO}_{3}$ e RMS1 = 0,71. Esses dados indicam que condições ambientais desfavoráveis tornam o efeito de estresse de metais pesados no solo mais expressivo sobre a população microbiana ("estresse duplo"). A maior evidência desse comportamento é a correlação de $0,95^{*}$ entre teores de $\mathrm{Pb}$ total e a classe de bactérias mais resistentes (BTESP) no mês de menor temperatura média (maio). O estresse provocado por metais pesados induz a variação da população de bactérias em favor dos organismos esporuláveis, que são mais resistentes (Duxbury \& Bicknell, 1983).

O solo 5 apresentou os menores valores de RMS1, fato que deve ter ocorrido pela grande quantidade de resíduos grosseiros do beneficiamento de $\mathrm{Pb}$ na superfície e incorporado ao solo (Quadro 1), o que prejudicou a estruturação e diluiu as frações coloidais do solo (teor de argila variando de 41 a $144 \mathrm{~g} \mathrm{~kg}^{-1}$ entre as épocas de coleta - Quadro 2). Os coeficientes de correlação entre a RMS1 e a RMS2 com os teores de argila e de C orgânico foram significativos (Quadro 6). A atividade microbiana também foi dependente dos teores de nutrientes do solo (r entre RMS1 e RMS2 com soma de bases $(\mathrm{S})=0,92^{* * *}$ e $0,91^{* * * *}$, respectivamente, e com teor de $\mathrm{N}$ total $=0,84^{* * * *}$ e $0,82^{* * * *}$, respectivamente).

Observou-se que o solo 1 (referência) apresentou os maiores valores de CBMS (Quadro 5) e que, de forma geral, os valores de CBMS aumentaram com a proximidade do verão. Essa flutuação estacional da CBMS também foi observada por outros autores (Adachi et al., 2006). O solo 3, também com cobertura arbórea, características físicas semelhantes e com maior fertilidade que o solo 1 (Quadros 2 e 3), apresentou valores da CBMS sistematicamente inferiores. De acordo com o trabalho de Min Liau et al. (2006), teores de $\mathrm{Pb}$ acima de $500 \mathrm{mg} \mathrm{kg}^{-1}$ (extração nítrica/clorídrica) causaram declínio significativo no CBMS. Os teores de $\mathrm{Pb}$ extraído com $\mathrm{HNO}_{3} 0,5 \mathrm{~mol} \mathrm{~L}^{-1}$ do solo 3 variaram de 9.467 a $14.457 \mathrm{mg} \mathrm{kg}^{-1}$ (Quadro 4). Outros estudos mostraram que altas concentrações de metais pesados diminuem o CBMS (Fliebbach et al., 1994; Barajas et al., 1999).

O gráfico gerado da análise por componentes principais (ACP) explicou 67,6 \% do comportamento microbiológico (10 variáveis), tomando as componentes 1 e 2 (Figura 3). Nota-se que três grupos distintos foram formados basicamente em função do mês de coleta, com exceção dos meses de novembro e setembro, os quais se misturaram na parte superior do gráfico de ordenação das amostras (scores) (Figura 3a). Com isso, percebe-se que as variáveis microbiológicas são muito mais suscetíveis às variações climáticas do que à qualidade dos solos. As amostras coletadas em maio formaram um grupo bastante homogêneo no quadrante direito inferior.

As variáveis que proporcionaram a separação desses grupos podem ser visualizadas na figura $3 \mathrm{~b}$, em função da posição similar das variáveis microbiológicas nos quadrantes do gráfico de ordenação das variáveis (loadings) e das amostras no gráfico de scores (Figura 3a). A formação do grupo das amostras coletadas em maio foi influenciada sobretudo pela percentagem de bactérias esporuláveis (BTESP \%), a qual foi muito superior nesta coleta (Quadro 5). Já a respiração e a população microbiana do solo (BT, BTESP e FGS) (Figura 3b e Quadro 5) foram as variáveis mais importantes para o agrupamento das amostras do mês de janeiro no quadrante inferior esquerdo do gráfico. As amostras dos solos 1 e 2 em janeiro, em função dos maiores valores para esses atributos, formaram um grupo distinto. 

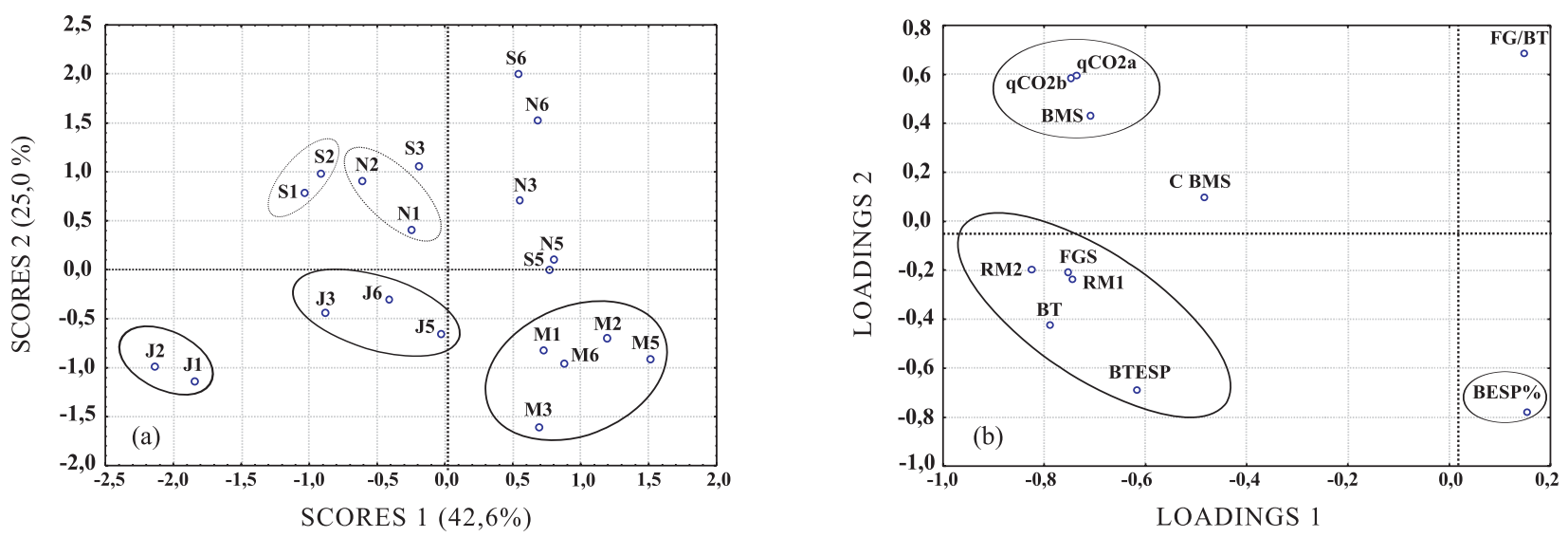

Figura 3. Análise de Componente Principal dos atributos microbiológicos da camada de 0 a 5 cm: diagrama de ordenação das amostras (scores) e formação de grupos de amostras semelhantes (a) e diagrama de ordenamento das variáveis (loadings) (b) levando-se em consideração as componentes principais 1 e 2. Nota: Na figura (a) a letra representa o mês de coleta e, o número, o solo. M: maio; S: setembro; N: novembro; J: janeiro.

A dispersão das amostras coletadas em setembro e novembro, no lado superior do gráfico (Figura 3a), foi influenciada, principalmente, pelos quocientes metabólicos e pelo CBMS, bem como por sua respectiva percentagem de $\mathrm{C}$ (Figura $3 \mathrm{~b})$. As condições ambientais dos meses de setembro e novembro foram mais próximas em relação às demais coletas (Figura 1), o que impossibilitou uma separação mais clara entre esses dois meses de amostragem.

Tomando os valores médios dos índices de qualidade ambiental microbiológicos (IQAMi) das amostras (Quadro 7), tem-se a sequência para época de amostragem: janeiro > novembro > setembro > maio. Apesar do grande efeito climático sobre os atributos microbiológicos, com base nos valores do IQAMi, com a média das épocas de coleta foi possível estabelecer a seguinte ordem decrescente de qualidade entre os solos: $1>2>3 \sim 5>6$. Esperava-se que o solo 6

Quadro 7. Valores de índices de qualidade ambiental micobiológicas para a camada de 0 a 5 e de 5 a $10 \mathrm{~cm}$

\begin{tabular}{lrrrrr}
\hline & \multicolumn{5}{c}{ Coleta } \\
\cline { 2 - 6 } Solo & Maio & Setembro & Novembro & Janeiro & Média \\
\hline & & & 0 a $5 \mathrm{~cm}$ & & \\
1 & 3,3 & 26,9 & 32,0 & 55,4 & 29,4 \\
2 & 1,5 & 21,0 & 30,8 & 52,3 & 26,4 \\
3 & 3,8 & 16,0 & 11,9 & 32,3 & 16,0 \\
5 & 0,7 & 9,7 & 13,1 & 33,3 & 14,2 \\
6 & 2,5 & 5,4 & 7,1 & 23,0 & 9,5 \\
& & & & & \\
1 & 22,5 & 24,9 & 24,7 & 24,6 & 24,2 \\
2 & 22,7 & 25,1 & 32,0 & 24,1 & 25,9 \\
3 & 22,7 & 23,0 & 23,2 & 22,9 & 23,0 \\
5 & 22,8 & 22,8 & 22,2 & 22,7 & 22,6 \\
6 & 22,5 & 23,4 & 23,9 & 22,6 & 23,1 \\
\hline
\end{tabular}

apresentasse maior desempenho em função de seus menores teores de $\mathrm{Pb}$ e Zn (Quadro 4); entretanto, seu menor IQAMi, possivelmente, refletiu a sua pior qualidade física e química (Quadros 2 e 3 ). Os menores IQAMi dos solos 3 e 5, em relação ao solo 1 (referência), devem-se, respectivamente, aos maiores teores de $\mathrm{Pb}$ extraídos com $\mathrm{HNO}_{3}$ (Quadro 4) e à grande ocorrência de rejeitos do tamanho areia no perfil do solo.

As variáveis físicas que possuem comportamento mais linear com o IQAMi (Quadro 8) são a umidade $\left(\mathrm{R}^{2}=0,72^{*}\right)$, seguida do teor argila $\left(\mathrm{R}^{2}=0,60^{*}\right)$ e da capacidade de campo $\left(\mathrm{R}^{2}=0,59^{*}\right)$. Em relação às variáveis químicas, tem-se o $\mathrm{Mg}^{2+}\left(\mathrm{R}^{2}=0,87^{* *}\right), \mathrm{N}$ total $\left(\mathrm{R}^{2}=0,58\right)$ e $\mathrm{C}$ orgânico $\left(\mathrm{R}^{2}=0,51\right)$. Os coeficientes de determinação entre IQAMi e os teores de $\mathrm{Pb}$ e $\mathrm{Zn}$ foram insignificantes. Ao subtrair as amostras do solo 6 (arenoso) das regressões lineares entre IQAMi e teor de $\mathrm{Pb}$ total, o valor de $\mathrm{R}^{2}$ aumentou de 0,11 (Quadro 8) para $0,96^{* * *}(y=-1169,4 \mathrm{x}+36123)$.

\section{Indicadores microbiológicos na profundidade de 5 a $10 \mathrm{~cm}$}

Devido, principalmente, às condições químicas mais desfavoráveis (Quadro 3), verificou-se na profundidade de 5 a $10 \mathrm{~cm}$ (Quadro 9) menor atividade microbiana em relação à camada mais superficial dos solos (Quadro 5): menores valores de CBMS, RMS1 e RMS2.

A camada de 5 a $10 \mathrm{~cm}$ está menos sujeita à variação de umidade e temperatura em função de época de amostragem, o que resultou em atributos microbiológicos mais uniformes, sem incremento da atividade na coleta em janeiro, conforme observado para a camada de 0 a $5 \mathrm{~cm}$.

Os altos valores de RMS (RMS1 e RMS2) para o solo 2 ocorridos em novembro (Quadro 9) provocou o isolamento de sua coleta de novembro (N2) no gráfico de ordenação das amostras (scores) da ACP, o que dificultou a formação de grupos. Portanto, realizou- 
se nova ACP sem essa amostra (Figura 4), que explicou 79,9 \% da variância dos dados. Observa-se que a formação de grupos por mês de coleta não é tão clara quanto para as análises microbiológicas da superfície, o que se deve, provavelmente, à menor

Quadro 8. Regressão linear entre as características físicas e químicas de maior correlação com as variáveis microbiológicas com a média (épocas de amostragem) do índice de qualidade ambiental microbiológico da camada de 0 a 5 e de 5 a $10 \mathrm{~cm}$ dos solos

\begin{tabular}{|c|c|c|}
\hline Variável & Equação & $\mathbf{R}^{2}$ \\
\hline \multicolumn{3}{|c|}{0 a $5 \mathrm{~cm}$} \\
\hline $\mathrm{Pb}$ total $\left(\mathrm{mg} \mathrm{kg}^{-1}\right)$ & $\hat{y}=-357,30 x+15781,0$ & 0,11 \\
\hline Capacidade de Campo (\%) & $\hat{y}=2,42 x-2,7$ & $0,59^{*}$ \\
\hline Umidade (\%) & $\hat{y}=1,78 x-4,5$ & $0,72^{*}$ \\
\hline Teor de argila $\left(\mathrm{g} \mathrm{kg}^{-1}\right)$ & $\hat{y}=1,84 x-3,1$ & $0,60^{*}$ \\
\hline Teor de $\mathrm{Mg}\left(\mathrm{cmol}_{\mathrm{c}} \mathrm{kg}^{-1}\right)$ & $\hat{y}=0,26 x-2,1$ & $0,87^{* *}$ \\
\hline C orgânico $\left(\mathrm{g} \mathrm{kg}^{-1}\right)$ & $\hat{y}=1,66 x-9,4$ & 0,51 \\
\hline $\mathrm{N}$ total $\left(\mathrm{g} \mathrm{kg}^{-1}\right)$ & $\hat{y}=0,29 x-1,1$ & 0,58 \\
\hline \multicolumn{3}{|c|}{5 a $10 \mathrm{~cm}$} \\
\hline $\mathrm{Pb}$ total $\left(\mathrm{mg} \mathrm{kg}^{-1}\right)$ & $\hat{y}=-2899,90 x+76611,0$ & 0,25 \\
\hline Capacidade de Campo (\%) & $\hat{y}=6,61 x-132,5$ & 0,47 \\
\hline Umidade (\%) & $\hat{y}=8,35 x-174,6$ & 0,55 \\
\hline Teor de argila $\left(\mathrm{g} \mathrm{kg}^{-1}\right)$ & $\hat{y}=9,36 x-197,7$ & $0,73^{*}$ \\
\hline Teor de $\mathrm{Mg}\left(\mathrm{cmol}_{\mathrm{c}} \mathrm{kg}^{-1}\right)$ & $\hat{y}=1,09 x-23,7$ & 0,54 \\
\hline Soma de bases $\left(\mathrm{cmol}_{\mathrm{c}} \mathrm{kg}^{-1}\right)$ & $\hat{y}=6,66 x-142,4$ & 0,56 \\
\hline CTC total $\left(\mathrm{cmol}_{\mathrm{c}} \mathrm{kg}^{-1}\right)$ & $\hat{y}=6,90 x-145,2$ & 0,53 \\
\hline C orgânico $\left(\mathrm{g} \mathrm{kg}^{-1}\right)$ & $\hat{y}=7,1192 x-139,05$ & 0,36 \\
\hline $\mathrm{N}$ total $\left(\mathrm{g} \mathrm{kg}^{-1}\right)$ & $\hat{\mathrm{y}}=1,357 \mathrm{x}-28,831$ & 0,47 \\
\hline
\end{tabular}

oscilação de umidade e temperatura da camada de 5 a $10 \mathrm{~cm}$ com as estações do ano.

O grupo formado pelas amostras de solo 1 nas coletas de setembro (S1), novembro (N1) e janeiro (J1) e de solo 2 na coleta de setembro (S2) (Figura 4a) foi separado em função dos maiores valores de respiração (RMS1 e RMS2) e quociente da atividade metabólica $\left(\mathrm{qCO}_{2} \mathrm{a}, \mathrm{b}\right)$ (Quadro 9 e Figura 4b). Conforme discutido para a profundidade de 0 a $5 \mathrm{~cm}$, esses solos apresentam melhores condições ambientais para o desenvolvimento microbiológico [solo 1 - menores teores e solo 2 - teores intermediários de $\mathrm{Pb}$ (Quadro 4); e características físicas e químicas adequadas (Quadros 2 e 3)]. As amostras do mês de maio formaram um grupo homogêneo, principalmente, devido aos menores valores de RMS.

A variação do IQAMi na profundidade de 5 a $10 \mathrm{~cm}$ dentro de um mesmo mês de coleta foi muito inferior às oscilações verificadas para $0 \mathrm{a} 5 \mathrm{~cm}$ (Quadro 7), o que indica menor capacidade de estratificação de qualidade ambiental quando se estudam camadas subsuperficiais de solo.

As relações entre o IQAMi e as variáveis físicas e químicas na camada de 5 a $10 \mathrm{~cm}$ foram semelhantes às apresentadas para a profundidade de 0 a $5 \mathrm{~cm}$ (Quadro 8). No que diz respeito aos metais pesados, também não se verificou ajuste na análise de regressão linear entre os teores de $\mathrm{Pb}$ com o IQAMi na camada de 5 a $10 \mathrm{~cm}$ (baixo valor de $\mathrm{R}^{2}$ ), mesmo com a exclusão da amostra 6.

Quadro 9. Atributos microbiológicos da camada de 5 a $10 \mathrm{~cm}$ dos $\operatorname{solos}^{(1)}$

\begin{tabular}{|c|c|c|c|c|c|c|c|}
\hline \multirow{2}{*}{ Coleta } & \multirow{2}{*}{ Solo } & \multicolumn{2}{|c|}{ Respiração microbiana } & \multirow{2}{*}{ CBMS } & \multirow{2}{*}{ CBMS } & \multirow{2}{*}{$\mathrm{qCO} 2 \mathrm{a}$} & \multirow{2}{*}{$\mathrm{qCO} 2 \mathrm{~b}$} \\
\hline & & RMS1 & RMS2 & & & & \\
\hline & & \multicolumn{2}{|c|}{$\mathrm{mg} \mathrm{C}-\mathrm{CO}_{2} \mathrm{~kg}^{-1} \mathrm{SS} \mathrm{h}^{-1}$} & $\mathrm{mg} \mathrm{C} \mathrm{kg}^{-1} \mathrm{SS}$ & $\%$ & & \\
\hline Maio & $\begin{array}{l}1 \\
2 \\
3 \\
5 \\
6\end{array}$ & $\begin{array}{l}0,20 \\
0,27 \\
0,26 \\
0,32 \\
0,18\end{array}$ & $\begin{array}{l}0,14 \\
0,17 \\
0,18 \\
0,19 \\
0,13\end{array}$ & $\begin{array}{l}\text { nd } \\
\text { nd } \\
\text { nd } \\
\text { nd } \\
\text { nd }\end{array}$ & $\begin{array}{l}\text { nd } \\
\text { nd } \\
\text { nd } \\
\text { nd } \\
\text { nd }\end{array}$ & $\begin{array}{l}\text { nd } \\
\text { nd } \\
\text { nd } \\
\text { nd } \\
\text { nd }\end{array}$ & $\begin{array}{l}\text { nd } \\
\text { nd } \\
\text { nd } \\
\text { nd } \\
\text { nd }\end{array}$ \\
\hline Setembro & $\begin{array}{l}1 \\
2 \\
3 \\
5 \\
6\end{array}$ & $\begin{array}{l}0,52 \\
0,56 \\
0,17 \\
0,14 \\
0,07\end{array}$ & $\begin{array}{l}0,44 \\
0,47 \\
0,13 \\
0,13 \\
0,06\end{array}$ & $\begin{array}{r}260,6 \\
266,7 \\
218,9 \\
262,4 \\
44,3\end{array}$ & $\begin{array}{l}0,56 \\
0,58 \\
0,56 \\
1,41 \\
0,72\end{array}$ & $\begin{array}{l}1,99 \\
2,08 \\
0,78 \\
0,52 \\
1,56\end{array}$ & $\begin{array}{l}1,70 \\
1,76 \\
0,59 \\
0,50 \\
1,33\end{array}$ \\
\hline Novembro & $\begin{array}{l}1 \\
2 \\
3 \\
5 \\
6\end{array}$ & $\begin{array}{l}0,70 \\
2,57 \\
0,19 \\
0,05 \\
0,08\end{array}$ & $\begin{array}{l}0,58 \\
1,47 \\
0,15 \\
0,04 \\
0,07\end{array}$ & $\begin{array}{r}663,0 \\
457,1 \\
218,3 \\
667,1 \\
37,1\end{array}$ & $\begin{array}{l}1,46 \\
1,05 \\
0,67 \\
4,38 \\
0,43\end{array}$ & $\begin{array}{l}1,05 \\
5,62 \\
0,88 \\
0,08 \\
2,27\end{array}$ & $\begin{array}{l}0,87 \\
3,21 \\
0,71 \\
0,06 \\
1,87\end{array}$ \\
\hline Janeiro & $\begin{array}{l}1 \\
2 \\
3 \\
5 \\
6\end{array}$ & $\begin{array}{l}0,60 \\
0,51 \\
0,21 \\
0,09 \\
0,14\end{array}$ & $\begin{array}{l}0,52 \\
0,44 \\
0,16 \\
0,10 \\
0,10\end{array}$ & $\begin{array}{l}480,2 \\
569,8 \\
421,6 \\
186,1 \\
406,5\end{array}$ & $\begin{array}{l}0,82 \\
1,35 \\
1,03 \\
0,82 \\
3,28\end{array}$ & $\begin{array}{l}1,26 \\
0,90 \\
0,50 \\
0,49 \\
0,34\end{array}$ & $\begin{array}{l}1,09 \\
0,76 \\
0,38 \\
0,51 \\
0,25\end{array}$ \\
\hline
\end{tabular}

(1) nd: valores não determinados por problemas analíticos com as amostras na coleta do mês de maio. 

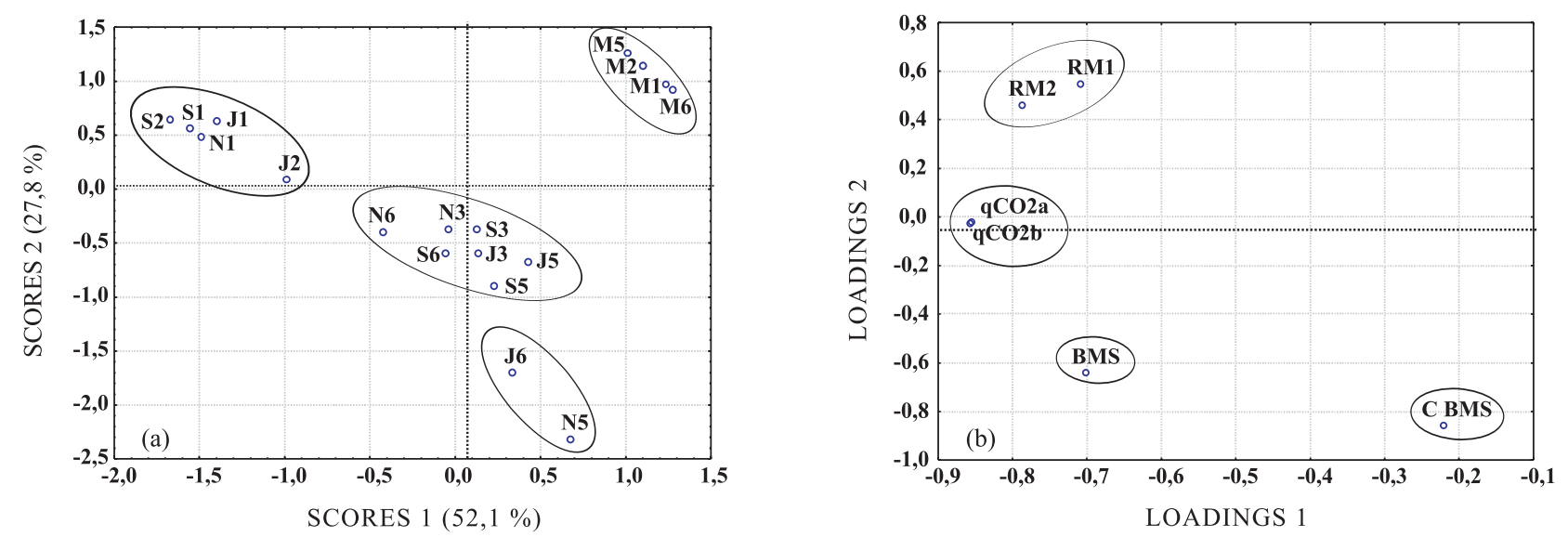

Figura 4. Análise de Componente Principal dos atributos microbiológicos da camada de 5 a 10 cm: diagrama de ordenação das amostras (scores) e formação de grupos de amostras semelhantes (a) e diagrama de ordenamento das variáveis (loadings) (b) levando-se em consideração as componentes principais 1 e 2. Nota: Na figura (a) letra representa o mês de coleta e, o número, o solo. M: maio; S: setembro; N: novembro; J: janeiro.

\section{CONCLUSÕES}

1. A população e a atividade microbiana do solo foram fortemente influenciadas pela condição climática e pela fertilidade dos solos. Contudo, no mês de maior estresse climático (menor temperatura), solos com maiores teores de $\mathrm{Pb}$ apresentaram menor população e atividade microbiana, ou seja, nessas condições as bactérias e os fungos foram bons indicadores de qualidade de solo.

2. A maior proporção de bactérias esporuláveis nos solos mais contaminados por $\mathrm{Pb}$ no mês mais frio (correlação de $0,95^{*}$ para maio) pode ser interpretada como mecanismo de resistência desses organismos.

3. Para estratificação de qualidade ambiental, com base nas características microbiológicas, deve-se preferir a camada mais superficial de solo (0 a $5 \mathrm{~cm}$ ).

4. O índice de qualidade ambiental microbiológico na camada de 0 a $5 \mathrm{~cm}$ foi mais eficiente que a análise por componentes principais (ACP) na separação dos solos contaminados com $\mathrm{Pb}$ e Zn. Já na profundidade de 5 a $10 \mathrm{~cm}$ a ACP foi mais eficiente para esse propósito.

\section{LITERATURA CITADA}

ACCIOLY, A.M.A. \& SIQUEIRA, J.O. Contaminação química e biorremediação do solo. In: NOVAIS, R.F.; ALVAREZ V., V.H. \& SCHAEFER, G.R., eds. Tópicos em ciência do solo. Viçosa, MG, Sociedade Brasileira de Ciência do Solo, 2000.v.1. p.299-351.

ADACHI, M.; BEKKU, Y.S.; RASHIDAH, W.; OKUDA, T. \& KOIZUMI, H. Differences in soil respiration between different tropical ecosystems. Applied Soil Ecol., 34:258$265,2006$.
ANDERSON, J.P.E. Soil respiration. In: PAGE, A.L; MILLER, R.H. \& KEENEY, D.R. eds. Methods of soil analysis; Chemical and microbiological properties. 2.ed. Madison, Soil Science Society of American, 1982. Part 2. p.831-871.

ANDRADE, M.G.; MELO, V.F.; GABARDO, J.; SOUZA, L.C.P. \& REISSMANN, C.B. Metais pesados em solos de área de mineração e metalurgia de chumbo: I - fitoextração. R. Bras. Ci. Solo, 33:1879-1888, 2009a.

ANDRADE, M.G.; MELO, V.F.; SOUZA, L.C.P.; GABARDO, J. \& REISSMANN, C.B. Metais pesados em solos de área de mineração e metalurgia de chumbo: I - formas e disponibilidade. R. Bras. Ci. Solo, 33:1889-1897, 2009 b.

BARAJAS, A.M.; GRACE, C.; ANSORENA, J.; DENDOOVEN, L. \& BROOKES, P.C. Soil microbial biomass and organic $\mathrm{C}$ in a gradient of zinc concentrations in soils around a mine spoil tip. Soil Biol. Biochem., 31:867-876, 1999.

BARROS, Y.B. Indicadores biológicos de qualidade de solos de área de mineração e processamento de chumbo, no município de Adrianópolis (PR). Curitiba, Universidade Federal do Paraná, 2008. 109p. (Tese de Mestrado)

BIDERBECK, V.O.; CAMPBELL, C.A. \& ZENTHEN, R.P. Effect of crop rotation and fertilization on some biological properties of a loam in southwestern Sakatchewam. Can. J. Soil Sci., 64:355-367, 1984.

CARDOSO, E.J.B.N. Ecologia microbiana do solo. In: CARDOSO, E.J.B.N.; TSAI, S.M. \& NEVES, M.C.P. eds. Microbiologia do Solo. Campinas, Sociedade Brasileira de Ciência do Solo, 1992. p.33-39.

CHAUDRI, A.M.; McGRATH, S.P. \& GILLER, K.E. Metal tolerance of isolates Rhizobium leguminosarum biovar trifolli from soil contaminated by past applications of sewage sludge. Soil Biol. Biochem., 24:83-88, 1992.

CHEW, I.; OBBARD, J.P. \& STANFORTH, R.R. Microbial cellulose decomposition in soils from a rifle range contaminated with heavy metals. Environ. Pollution, 111:367-375, 2001. 
DICK, R.P.; BREAKWILL, D. \& TURCO, R. Soil enzyme activities and biodiversity measurements as integrating biological indicators. In: DORAN, J.W. \& JONES, A.J. eds. Handbook of methods for assessment of soil quality. Madison, Soil Science Society of America Specific Publications, 1996. p. 242-272.

DOELMAN, P.; JANSEN, E.; MICHELS, M. \& TIL, van M. Effects of heavy metals in soil on microbial diversity and activity as shown by the sensitivity-resistance index, an ecologically relevant parameter. Biol. Fert. Soils, 17:177184, 1994.

DUXBURY, T. \& BICKNELL, B. Metal-tolerant bacterial populations from natural and metal-polluted soils. Soil Biol. Biochem., 15:243-250. 1983.

EMPRESA BRASILEIRA DE PESQUISA AGROPECUÁRIA . EMBRAPA. Manual de métodos de análise de solo. 2.ed. Rio de Janeiro, Embrapa - CNPS, 1997. 209p.

EYSINK, G.G.J. Metais pesados no Vale do Ribeira e em Igunde-Cananéia. R. CETESB Tecnol., 2:6-13, 1988.

FLIEBBACH, A.; MARTENS, A. \& REBER, H.H. Soil microbial biomass and microbial activity in soils treated with heavy metal contaminated sewage-sludge. Soil Biol. Biochem., 26:1201-1205, 1994.

FRIGHETTO, R. T. S. \& VALARINI, P. J. Indicadores biológicos e bioquímicos da qualidade do solo. Jaguariúna, Embrapa Meio Ambiente, 2000. 118p.

GELADI, P.; ISAKSSON, H.L.; LINDQVIST, WOLD, S. \& ESBENSEN, K. Principal component analysis of multivariate images. Chemometrics Intell. Lab. Syst., 5: 209-220, 1989 .

GRISI, B.M. Biomassa e a atividade de microrganismos do solo: revisão metodológica. R. Nord. Biol., 10:1-22, 1995.

HEINEMEYER, O.; INSAM, H.; KAISER, E.A. WALENZIK, A. Soil microbial biomass and respiration measurements: an automated technique based on infra-red gas analysis. Plant Soil, 116:191-195.1989.

HIRSCH, P.R.; JONES, M.J.; McGRATH, S.P. \& GILLER, K.E. Heavy metals from past applications of sewage sludge the genetic diversity of Rhizobium leguminosarum biovar trifolli populations. Soil Biol. Biochem., 25:1485-1490, 1993.

JACKSON, M.L. Análisis química de suelos. 2.ed. Barcelona, Omega, 1970. p. 254-267.

KNUDSEN, D.; PETERSON, G.A. \& PRATT, P.F. Lithium, sodium, and potassium. In: PAGE, A.L., ed. Methods of soil analysis. Chemical and microbiological properties. Madison, American Society of Agronomy, 1986. p.225246.

LANDMEYER, J.E.; BRADLEY, P.M. \& CHAPELLE, F.H Influence of $\mathrm{Pb}$ on microbial activity in $\mathrm{Pb}$-contaminated soils. Soil Biol. Biochem., 25:1465-1466, 1993.

LEE, I.S.; KIM, O.K.; CHANG, Y.Y.; BAE, B.; KIM, H.H. \& BAEK, K.H. Heavy metal concentrations and enzyme activities in soil from a contaminated Korean shooting range. J. Biosci. Bioeng., 94:406-411. 2002.
LIAO, M.; CHEN, C.L. \& HUANG, C.Y. Effect of heavy metals on soil microbial activity and diversity in a reclaimed mining wasteland of red soil area. Chinese J. Environ. Sci., 17:832-837. 2005.

LIM, C.H. \& JACKSON, M.L. Dissolution for total elemental analysis. In: PAGE, A.L. ed. Methods of soil analysis. Madison, American Society of Agronomy, 1986. p. 1-12.

MARTINS, R.; MELO, V.F. \& MONTE SERRAT, B. Métodos de determinação da disponibilidade de potássio para a cultura do trigo em solos dos Campos Gerais, Estado do Paraná. R. Ceres, 51:787-801, 2004.

MELO, V.F.; SCHAEFER, C.E.G.R.; NOVAIS, R.F.; SINGH, B. \& FONTES, M.P.F. Potassium and magnesium in clay minerals of some Brazilian soil as indicated by a sequential extraction procedure. Comm. Soil Sci. Plant Anal., 33:2203$2225,2002$.

MENZIES, J.D.F. Fungi. In: BLACK, C.A., ed. Methods of soil analysis. Madison, American Society of Agronomy, v.2, 1965. p.1502-1505.

MERGEAY, M. Heavy metal resistances in microbial ecosystems. In: AKKERMANS, A.D.L.; VAN ELSAS, J.D. \& BRUIJN, F.J., eds. Molecular microbial ecology manual. London, Kluwer Academic Publishers, 1995. p.1-17.

MIN LIAU; CHENG-LI CHEN; LU-SHENG ZENG \& CHANGYONG HUANG. Influence of lead acetate on soil microbial biomass and community structure in two different soils with the growth of Chinese cabbage (Brassica chinensis). Chemosphere (2006), doi:10.1016/j.chemosphere. 2006.07.046.

MOREIRA, F.M.S. \& SIQUEIRA, J.O. Microbiologia e bioquímica do solo. Lavras, Universidade Federal de Lavras, 2002. 625p.

MUNN, K. J.; EVANS, J. \& CHALK, P. M. Mineralization of soil and legume nitrogen in soils treated with metalcontaminated sewage sludge. Soil Biol. Biochem., 32:20312043,2000

OBBARD, J.P. \& JONES, K.C. The effect of heavy metals on dinitrogen fixation by Rhizobium -white clover in a range of long-term sewage sludge amended and metalcontaminated soils. Environ. Pollution, 79:105-112. 1993.

OLSEN, S.R. \& SOMMERS, L.E. Phosphorus. In: PAGE, A.L.; MILLER, R.H. \& KEENEY, D.R., eds. Chemical and microbiological properties. 2.ed. Madison, American Society of Agronomy, 1982. p. 421-422.

OLIVEIRA, M.A.F.; MANIESI, V.; TEIXEIRA, W. \& DAITX, E.C. Caracterização Isotópica de Metabasitos e Anfibolitos dos Grupos Açungui e Setuva na Porção Sul da Faixa Ribeira. Geol. USP Série Científica, 2:161-170, 2002.

PAPENDICK, R. \& PARR, J.F. Soil quality: The key to a sustainable agriculture. Am. J. Alternative Agric., 7:2-3, 1992.

PARKINSON, E.S.; GRAY, T.R.G.; WILLIANS, S.T. Methods for studying the ecology of soil microorganisms. Oxford, Adlard, 1971. 116p.

REBER, H.H. Simultaneous estimates of the diversity and the degradative ability of heavy-metal-affected soil bacterial communities. Biol. Fert. Soils, 13:181-186, 1992. 
RIBEIRO, M.C. \& SOARES, M.M. Microbiologia prática: Roteiro e manual; bactérias e fungos. São Paulo, Editora Atheneu, 2002. 112p.

SIQUEIRA, J.O.; MOREIRA, F.M.S.; GRISS, B.M.; HUNGRIA, M. \& ARAÚJO. R.S. Microrganismos e processos biológicos do solo; Perspectiva ambiental. Brasília, Embrapa-SPI, 1994. $142 \mathrm{p}$

SUMMERS, A.O. \& SILVER, S. Microbial transformations of metals. Ann. Rev. Microbiol., 32:617-672, 1978.

TATE, K.R.; ROSS, D.J. \& FELTHAM, C.W. A direct extraction method to estimate soil microbial C: effects of experimental variables and some different calibration procedures. Soil Biol. Biochem., 20:329-335, 1988.

SOON, Y.K \& BATES, T.E. Chemical pools of $\mathrm{Cd}$, Ni, and $\mathrm{Zn}$ in polluted soils and some preliminary indications of their availability to plants. J. Soil Sci., 33:477-488, 1982.
UNIVERSIDADE FEDERAL DO PARANÁ - UFPR. Manual de diagnóstico de fertilidade e manejo de solos agrícolas. 2.ed. Curitiba, Imprensa Universitária da UFPR, 2003. 143p.

VALSECCHI, G.; GIGLIOTTI, C. \& FARINI, A. Microbial biomass, activity and organic matter accumulation in soils contaminated with heavy metals. Biol. Fert. Soils, 20:253259, 1995.

VANCE, E.D.; BROOKES, P.C. \& JENKINSON, D.S. An extraction method for measuring soil microbial biomass. C. Soil Biol. Biochem., 19:703-707, 1987.

WALKER, J. \& REUTER, D.J. Indicators of catchments health: A technical perspective. Melbourne, CSIRO, 1996. 174p.

WOLLUM II, A.G. The cultural methods for soil microorganisms. In: MILLER, R.H. \& KEENEY, D.R., eds. Methods of soil analysis: Chemical and microbiological properties. Madison, Soil Science Society of American, 1982. p.781-802. 